\title{
Production of Hydrogen and Sulfur from Hydrogen Sulfide in a Nonthermal-Plasma Pulsed Corona Discharge Reactor
}

\author{
Morris D. Argyle \\ mdargyle@byu.edu \\ Gui-Bing Zhao \\ Sanil John \\ Ji-Jun Zhang \\ Jerry C. Hamann
}

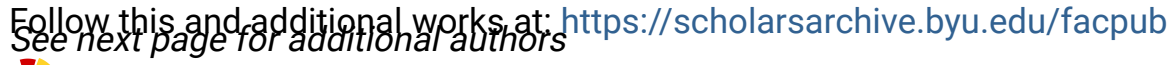

Part of the Chemical Engineering Commons

\section{Original Publication Citation}

G.B. Zhao, S. John, J.J. Zhang, J.C. Hamann, S. Muknahallipatna, S. Legowski, J.F. Ackerman, M.D. Argyle, "Production of Hydrogen and Sulfur in Hydrogen Sulfide in a Nonthermal-Plasma Pulsed Corona Discharge Reactor." Chemical Engineering Science, 62, 2216-2227, 27. http://www.sciencedirect.com/science/journal/9259/62/8

\section{BYU ScholarsArchive Citation}

Argyle, Morris D.; Zhao, Gui-Bing; John, Sanil; Zhang, Ji-Jun; Hamann, Jerry C.; Muknahallipatna, Suresh S.; Legowski, Stanislaw; and Ackerman, John F., "Production of Hydrogen and Sulfur from Hydrogen Sulfide in a Nonthermal-Plasma Pulsed Corona Discharge Reactor" (2007). Faculty Publications. 263.

https://scholarsarchive.byu.edu/facpub/263

This Peer-Reviewed Article is brought to you for free and open access by BYU ScholarsArchive. It has been accepted for inclusion in Faculty Publications by an authorized administrator of BYU ScholarsArchive. For more information, please contact ellen_amatangelo@byu.edu. 


\section{Authors}

Morris D. Argyle, Gui-Bing Zhao, Sanil John, Ji-Jun Zhang, Jerry C. Hamann, Suresh S. Muknahallipatna, Stanislaw Legowski, and John F. Ackerman 


\title{
Production of Hydrogen and Sulfur from Hydrogen Sulfide in a Nonthermal-Plasma Pulsed Corona Discharge Reactor
}

\author{
Gui-Bing Zhao, ${ }^{1}$ Sanil John, ${ }^{1}$ Ji-Jun Zhang, ${ }^{1}$ Jerry C. Hamann, ${ }^{2}$ Suresh S. Muknahallipatna, ${ }^{2}$ \\ Stanislaw Legowski, ${ }^{2}$ John F. Ackerman, ${ }^{1}$ and Morris D. Argyle ${ }^{1 *}$ \\ (1) Department of Chemical \& Petroleum Engineering (2) Department of Electrical \& Computer \\ Engineering, University of Wyoming, 1000 E. University Avenue, Laramie, WY 82071
}

\begin{abstract}
Hydrogen sulfide $\left(\mathrm{H}_{2} \mathrm{~S}\right)$ dissociation into hydrogen and sulfur has been studied in a pulsed corona discharge reactor (PCDR). Due to the high dielectric strength of pure $\mathrm{H}_{2} \mathrm{~S}$ ( 2.9 times higher than air), a non-thermal plasma could not be sustained in pure $\mathrm{H}_{2} \mathrm{~S}$ at discharge voltages up to $30 \mathrm{kV}$ with our reactor geometry. Therefore, $\mathrm{H}_{2} \mathrm{~S}$ was diluted with another gas with lower dielectric strength to reduce the breakdown voltage. Breakdown voltages of $\mathrm{H}_{2} \mathrm{~S}$ in four balance gases (Ar, He, $\mathrm{N}_{2}$ and $\mathrm{H}_{2}$ ) have been measured at different $\mathrm{H}_{2} \mathrm{~S}$ concentrations and pressures. Breakdown voltages are proportional to the partial pressure of $\mathrm{H}_{2} \mathrm{~S}$ and the balance gas. With increasing $\mathrm{H}_{2} \mathrm{~S}$ concentrations, $\mathrm{H}_{2} \mathrm{~S}$ conversion initially increases, reaches a maximum, and then decreases. $\mathrm{H}_{2} \mathrm{~S}$ conversion and the reaction energy efficiency depend on the balance gas and $\mathrm{H}_{2} \mathrm{~S}$ inlet concentrations. $\mathrm{H}_{2} \mathrm{~S}$ conversion in atomic balance gases, such as $\mathrm{Ar}$ and $\mathrm{He}$, is more efficient than that in diatomic balance gases, such as $\mathrm{N}_{2}$ and $\mathrm{H}_{2}$. These observations can be explained by proposed reaction mechanisms of $\mathrm{H}_{2} \mathrm{~S}$ dissociation in different balance gases. The results show that nonthermal plasmas are effective for dissociating $\mathrm{H}_{2} \mathrm{~S}$ into hydrogen and sulfur.
\end{abstract}

\section{Originally submitted to Chem. Eng. Sci., Dec. 23, 2005 Revision submitted Dec. 12, 2006}

\footnotetext{
${ }^{*}$ Corresponding author. E-mail: mdargyle@uwyo.edu, tel: 307-766-2973, fax: 307-766-6777 1 Zhao- $\mathrm{H}_{2} \mathrm{~S} 15$ Chem. Eng. Sci
} 


\section{Introduction}

Gas streams containing hydrogen sulfide $\left(\mathrm{H}_{2} \mathrm{~S}\right)$ are encountered in almost all fossil fuel energy extraction and processing systems. The conventional treatment method for $\mathrm{H}_{2} \mathrm{~S}$ is the Claus process, which produces sulfur and water by the net reaction: $\mathrm{H}_{2} \mathrm{~S}+\mathrm{O}_{2} \rightarrow \mathrm{S}+\mathrm{H}_{2} \mathrm{O}$. The reaction is inefficient because the valuable potential product hydrogen $\left(\mathrm{H}_{2}\right)$ is converted into water. The transformation of hydrogen in a weakly bound state in $\mathrm{H}_{2} \mathrm{~S}$ to a strongly bound state in $\mathrm{H}_{2} \mathrm{O}$ results in the loss of a potential source of $\mathrm{H}_{2}$. Hydrogen sulfide would have a much higher economic value if both sulfur and chemically pure hydrogen could be recovered instead of merely sulfur. Therefore, processes for direct dissociation of $\mathrm{H}_{2} \mathrm{~S}$ into $\mathrm{H}_{2}$ and sulfur are desirable.

Many methods have been investigated to dissociate $\mathrm{H}_{2} \mathrm{~S}$ into its constituent elements, including thermal decomposition, both noncatalytic and catalytic, electrochemical methods, photochemical methods, and plasma methods (Zaman and Chakma, 1995). Compared to electrochemical and photochemical methods, thermal decomposition and plasma decomposition are promising because of relatively low energy consumption (Cox et al., 1998). However, the thermal decomposition reaction of $\mathrm{H}_{2} \mathrm{~S}$ is endothermic with low equilibrium conversions even at high temperatures (Kaloidas and Papayannakos, 1987). For example, thermal decomposition of $\mathrm{H}_{2} \mathrm{~S}$ has an equilibrium conversion of $12 \%$ at $1000^{\circ} \mathrm{C}$ and 1 atmosphere pressure that decreases to less than $1 \%$ at temperatures below $550^{\circ} \mathrm{C}$. Therefore, two methods have been proposed to overcome the thermodynamic limitation of $\mathrm{H}_{2} \mathrm{~S}$ conversion. One is product removal by condensation of the sulfur and separation of the hydrogen with membranes [Zaman and Chakma (1995) and references therein]. The other is creation of a nonthermal equilibrium environment for $\mathrm{H}_{2} \mathrm{~S}$ conversion, as found in nonthermal plasmas. Non-thermal plasmas are characterized by 
low gas temperature and high electron temperature wherein high energy electrons are produced in the gas while the bulk temperature of the gas is unchanged. A nonthermal plasma is a partially ionized gas that provides a source of chemically active species, including radicals, excited neutrals, and ions, that can promote chemical reactions at ambient temperatures. Therefore, nonthermal plasmas overcome the disadvantage of the need for high temperatures because the majority of the electrical energy goes into the production of energetic electrons rather than into gas heating. For reactions that are thermodynamically unfavorable and for which low equilibrium conversions are obtained at high reaction temperatures, nonthermal plasmas have an advantage over thermal processes because thermal equilibrium is not required to be achieved.

Direct dissociation of $\mathrm{H}_{2} \mathrm{~S}$ has been investigated using various plasma processing technologies, including arc discharge or thermal plasmas, microwave plasma, glow discharge, silent discharge, and pulsed corona discharge. Dalaine et al. (1998a,b) investigated $\mathrm{H}_{2} \mathrm{~S}$ conversion in gas systems with 0-100 $\mathrm{ppm}_{2} \mathrm{~S}$ in air using gliding arc discharges. This type of reactor is rather inefficient, with an energy consumption of $500 \mathrm{eV} / \mathrm{H}_{2} \mathrm{~S}$ molecule dissociated. The theoretical minimum energy requirement for the decomposition of $\mathrm{H}_{2} \mathrm{~S}$ is over three orders of magnitude less than this. For the reaction: $\mathrm{H}_{2} \mathrm{~S}(\mathrm{~g}) \rightarrow \mathrm{H}_{2}(\mathrm{~g})+\mathrm{S}(\mathrm{s}), \Delta \mathrm{H}_{298}=0.21 \mathrm{eV} / \mathrm{H}_{2} \mathrm{~S}=$ $20.3 \mathrm{~kJ} / \mathrm{mol}$. A large amount of work on microwave decomposition of $\mathrm{H}_{2} \mathrm{~S}$ has been carried out in the former Soviet Union (Asisov et al., 1985; Bagautdinov et al., 1992, 1993a,b, 1995, 1998), where both laboratory and pilot units were reportedly used for the decomposition of pure $\mathrm{H}_{2} \mathrm{~S}$ or mixtures with $\mathrm{CO}_{2}$ with a very low energy consumptions of $\sim 0.76 \mathrm{eV} / \mathrm{H}_{2} \mathrm{~S}$. Encouraged by these reports of high conversions and low energy requirements, a joint project for $\mathrm{H}_{2} \mathrm{~S}$ conversion using microwave plasmas was undertaken by The Alberta Hydrogen Research Program, the

3 
Atomic Energy of Canada, and Shell Canada Limited. Unfortunately, this group reported the energy consumption for $\mathrm{H}_{2} \mathrm{~S}$ conversion to be about $4.5 \mathrm{eV} / \mathrm{H}_{2} \mathrm{~S}$ (Cox et al., 1998) and thus was unable to reproduce the low energy consumption reported by the Russian researchers. All microwave plasma experiments for $\mathrm{H}_{2} \mathrm{~S}$ conversion were performed at pressures below 1 atmosphere, which requires additional energy consumption for compression and vacuum costs. Traus et al. $(1992,1993)$ investigated conversion of $\mathrm{H}_{2} \mathrm{~S}$ at $10-100 \%$ concentrations in $\mathrm{Ar}, \mathrm{N}_{2}$, and $\mathrm{H}_{2}$ in a silent discharge reactor and a rotating glow discharge reactor. They concluded that the energy consumption for $\mathrm{H}_{2} \mathrm{~S}$ conversion in a rotating glow discharge reactor $\left(\sim 27 \mathrm{eV} / \mathrm{H}_{2} \mathrm{~S}\right)$ is less than that in a silent discharge reactor $\left(\sim 81 \mathrm{eV} / \mathrm{H}_{2} \mathrm{~S}\right)$. In addition, Abolentsev et al. (1995) and Ma et al. (2001) investigated decomposition of low (ppm) concentrations of $\mathrm{H}_{2} \mathrm{~S}$ in different balance gases including air, $\mathrm{N}_{2}, \mathrm{H}_{2}$, He, and $\mathrm{CH}_{4}$ using a silent discharge reactor. $\mathrm{H}_{2} \mathrm{~S}$ conversion in pulsed corona discharge reactors was also investigated by several investigators (Helfritch, 1993; Ruan et al., 1999; Wiseman and Douglas, 1972; Averin et al., 1996). These investigations were conducted at low $\mathrm{H}_{2} \mathrm{~S}$ concentrations ( $\left.<2 \%\right)$ with high $\left(>100 \mathrm{eV} / \mathrm{H}_{2} \mathrm{~S}\right)$ energy consumption, which are not practical conditions for commercial application.

Despite this extensive research on $\mathrm{H}_{2} \mathrm{~S}$ conversion, many questions remain unanswered. First, all of the research described above has been performed either below atmospheric pressure or at low $\mathrm{H}_{2} \mathrm{~S}$ concentrations $(<2 \%) . \mathrm{H}_{2} \mathrm{~S}$ conversion at pressures above atmospheric and at high $\mathrm{H}_{2} \mathrm{~S}$ concentrations is desirable to determine if nonthermal plasmas have potential for industrial application.

Second, there are no reports on the breakdown voltage of $\mathrm{H}_{2} \mathrm{~S}$ at pressures higher than atmospheric and $\mathrm{H}_{2} \mathrm{~S}$ concentrations $>2 \%$. Gases at normal temperatures and pressures contain very low concentrations of current carriers (free electrons and ions) and therefore behave as 
insulators. In an electric field, any electrons or ions present are accelerated over a distance corresponding to their mean free path between collisions. If they gain enough kinetic energy to ionize gas molecules, they create new current carriers which in turn ionize more molecules. This avalanche-like process forms channels of conducting plasma called streamers. The electrical resistance of the gas between the electrodes becomes nearly zero. This transition of a gas between the insulating and conducting states is known as breakdown. The voltage at which it occurs is called the breakdown voltage. The specific breakdown voltage depends on the gas, as well as on the electrode geometry, the electrode composition, and the gas pressure (Lide, 2003). Breakdown voltage data are important because they define the operating limits for the reaction.

$\mathrm{H}_{2} \mathrm{~S}$ is an electronegative gas with a high dielectric strength of about 2.9 (Christophorou et al., 1987). Common gases like air, $\mathrm{N}_{2}, \mathrm{H}_{2}$, He, and Ar have very low dielectric strengths of 1 , 1, 0.5, 0.15, 0.18, respectively (Lide, 2003). Therefore, much higher applied voltages are required for electrical breakdown of $\mathrm{H}_{2} \mathrm{~S}$ compared to these gases in the same reactor geometry. In addition, electrons are accelerated over the mean free path of gas molecules during the process of electrical breakdown (Zhao et al., 2005a). As the mean free path of gas molecules increases with decreasing gas pressure, individual electrons gain more kinetic energy in low pressure plasmas than in high pressure plasmas under otherwise similar operating conditions (Zhao et al., 2005a), which causes the breakdown voltage of a gas to decrease with decreasing gas pressure. Therefore, the electrical breakdown of $\mathrm{H}_{2} \mathrm{~S}$ at either low pressure or low $\mathrm{H}_{2} \mathrm{~S}$ concentration in a balance gas with a low dielectric strength is comparatively easy, whereas, the electrical breakdown of $\mathrm{H}_{2} \mathrm{~S}$ at pressures above atmospheric and at high $\mathrm{H}_{2} \mathrm{~S}$ concentrations is more difficult. 
Third, the mechanism of $\mathrm{H}_{2} \mathrm{~S}$ conversion in the plasma is not clear. Since the ionization potential of $\mathrm{H}_{2} \mathrm{~S}(10.4 \mathrm{eV})$ is considerably lower than $\mathrm{He}(24.6 \mathrm{eV})$, $\operatorname{Ar}(15.8 \mathrm{eV}), \mathrm{N}_{2}(15.6 \mathrm{eV})$, $\mathrm{H}_{2}(15.4 \mathrm{eV}), \mathrm{CH}_{4}(12.6 \mathrm{eV}), \mathrm{O}_{2}(12.1 \mathrm{eV})$, and $\mathrm{H}_{2} \mathrm{O}$ (12.6 eV) (Lide, 2003), Ma et al.(2001) and Helfritch (1993) proposed that the $\mathrm{H}_{2} \mathrm{~S}$ conversion mechanism in any of these gases involves ionization of $\mathrm{H}_{2} \mathrm{~S}$ (e $+\mathrm{H}_{2} \mathrm{~S} \rightarrow \mathrm{H}_{2} \mathrm{~S}^{+}+2 \mathrm{e}$ ) and subsequent charge neutralization with dissociation $\left(\mathrm{H}_{2} \mathrm{~S}^{+}+\mathrm{e} \rightarrow \mathrm{HS}+\mathrm{H}\right)$. Abolentsev et al. (1995) proposed an alternate three step mechanism for $\mathrm{H}_{2} \mathrm{~S}$ conversion: (1) the balance gas (M) is ionized to $\mathrm{M}^{+}$, (2) $\mathrm{H}_{2} \mathrm{~S}^{+}$is formed by charge transfer reaction $\left(\mathrm{M}^{+}+\mathrm{H}_{2} \mathrm{~S} \rightarrow \mathrm{M}+\mathrm{H}_{2} \mathrm{~S}^{+}\right.$), and (3) $\mathrm{H}_{2} \mathrm{~S}$ is dissociated by reaction with an ionized $\mathrm{H}_{2} \mathrm{~S}$ molecule $\left(\mathrm{H}_{2} \mathrm{~S}^{+}+\mathrm{H}_{2} \mathrm{~S} \rightarrow \mathrm{H}_{3} \mathrm{~S}^{+}+\mathrm{HS}\right)$. However, neither of these mechanisms may appropriately represent the actual process because the ionization degree in nonthermal plasmas is quite low. A recent investigation by Zhao et al. (2006a) showed that ionization reactions in nonthermal plasmas are negligible. Alternately, Traus et al. $(1992,1993)$ proposed that radicals, such as $\mathrm{H}$ and HS, formed in the plasma are responsible for $\mathrm{H}_{2} \mathrm{~S}$ conversion.

Therefore, the goals of this work are to investigate breakdown voltage and conversion mechanism of $\mathrm{H}_{2} \mathrm{~S}$ in four balance gases ( $\mathrm{Ar}, \mathrm{He}, \mathrm{N}_{2}$, and $\mathrm{H}_{2}$ ) in a pulsed corona discharge reactor (PCDR) at higher pressures (above atmospheric) and $\mathrm{H}_{2} \mathrm{~S}$ concentrations ( $\geq 4 \%$ ) than previously reported. A PCDR was chosen to investigate $\mathrm{H}_{2} \mathrm{~S}$ conversion because (1) PCD plasmas have been extensively investigated and used in methane (Yao et al., 2001) and $\mathrm{NO}_{\mathrm{x}}$ conversion (Zhao et al., 2004a,b, 2005b,c) and (2) comparison of energy efficiency of methane conversion among three types of nonthermal plasma reactors (PCD, microwave, and silent discharge) shows that PCD reactors are one to two orders of magnitude more energy efficient than the other two (Zhao et al., 2006b). 


\section{Experimental Section}

Figure 1 shows a diagram of the experimental system. The system consists of a reactor with an electrical system built around a thyratron switch, a flow control and distribution system, and a gas sampling system. The reactor was oriented vertically, with the gas flow from bottom to top. The electrical system can deliver charge voltages from $6.9 \mathrm{kV}$ to $30 \mathrm{kV}$ at pulse frequencies from 0 to $1000 \mathrm{~Hz}$. The capacitor bank provides space for four doorknob capacitors in increments of $640 \mathrm{pF}$. The capacitors were charged to the desired voltage using a $40 \mathrm{kV}$ oilcooled high voltage power supply. On triggering the thyratron, the stored energy in the capacitors is discharged in a few nanoseconds to the anode, giving rise to a high rate of change of voltage (dv/dt) on the anode. This process of charging and discharging the capacitors is repeated based on the thyratron trigger frequency, leading to sustained current streamers or plasma. Electrical breakdown during corona discharge can be detected by a discharge waveform recorder. The cathode was a stainless steel tube with $0.024 \mathrm{~m}$ in diameter and $0.914 \mathrm{~m}$ in length, while the anode was a stainless steel wire $0.001 \mathrm{~m}$ in diameter passing axially through the center of the tube. The wire was positively charged, while the tube was grounded. The gas flowing through the reactor tube was converted to plasma by the high voltage discharge from the reactor anode. A sulfur trap immersed in ice water at the reactor discharge was filled with stainless steel wool to enhance heat transfer and surface area for sulfur vapor removal from the exit gas.

The four gas mixtures of $\mathrm{H}_{2} \mathrm{~S}$ in $\mathrm{Ar}, \mathrm{H}_{2} \mathrm{~S}$ in $\mathrm{He}, \mathrm{H}_{2} \mathrm{~S}$ in $\mathrm{N}_{2}$, and $\mathrm{H}_{2} \mathrm{~S}$ in $\mathrm{H}_{2}$ were prepared by mixing ultra high purity (UHP) $\mathrm{H}_{2} \mathrm{~S}$ with the UHP balance gas. Gas mixtures flowed through PCDR at entrance conditions of ambient temperature $(\sim 300 \mathrm{~K})$ and a controlled pressure. The highest pressure used in this work was 5.0 bar. The desired entrance mole fraction of $\mathrm{H}_{2} \mathrm{~S}$ was achieved by setting flowrates of $\mathrm{H}_{2} \mathrm{~S}$ and the balance gas using two well-calibrated mass flow 
controllers. The energy released by the capacitors per pulse was calculated from $1 / 2 \mathrm{CV}_{\mathrm{c}}{ }^{2}$, where C is the pulse forming capacitance, fixed at $1920 \mathrm{PF}$ in this work, and $\mathrm{V}_{\mathrm{c}}$ is the constant charge voltage before discharge. The power consumed, $\mathrm{W}\left(\mathrm{J} \cdot \mathrm{s}^{-1}\right)$, was calculated as the product of the input energy per pulse and the pulse frequency, $1 / 2 \mathrm{fCV}_{\mathrm{c}}{ }^{2}$, where $\mathrm{f}$ is the pulse frequency in $\mathrm{Hz}$. The gas leaving the sulfur condenser was analyzed using an online Residual Gas Analyzer (RGA, Stanford Research Systems, Inc. QMS100), which is a quadrupole mass spectrometer. To perform quantitative measurements, an internal standard method (Watson, 1997) was used to calibrate the ion signal response at an $\mathrm{m} / \mathrm{z}$ ratio of 34 with the $\mathrm{H}_{2} \mathrm{~S}$ mole fraction, in which the balance gas was used as an internal standard. The calibration results are shown in Figure 2.

Figure 2 shows the ratio of the $\mathrm{H}_{2} \mathrm{~S}$ and balance gas mole fractions as a function of the measured $\mathrm{H}_{2} \mathrm{~S}$ and balance gas intensities, which show a linear relationship:

$$
\frac{y_{H_{2} S}}{y_{B}}=a \cdot \frac{I_{H_{2} S}}{I_{B}}+b
$$

where $\mathrm{y}$ is the mole fraction of gas, $\mathrm{I}$ is the ion current from RGA, and the subscript B represents the balance gas of $\mathrm{Ar}, \mathrm{He}, \mathrm{N}_{2}$, of $\mathrm{H}_{2}$. Therefore, the measured ion current ratio of $\mathrm{H}_{2} \mathrm{~S}$ and the balance gas can be used to determine the mole fraction ratio, $\mathrm{K}$, of $\mathrm{H}_{2} \mathrm{~S}$ and the balance gas from Figure 2. For a binary gas mixture at the reactor entrance, the mole fraction of $\mathrm{H}_{2} \mathrm{~S}$ and the balance gas can be calculated from

$$
\begin{gathered}
y_{i, H_{2} S}=\frac{K_{i}}{K_{i}+1} \\
y_{i, B}=\frac{1}{K_{i}+1}
\end{gathered}
$$

where the subscript $\mathrm{i}$ represents the inlet gas. When the corona discharge is on, $\mathrm{H}_{2} \mathrm{~S}$ dissociates into $\mathrm{H}_{2}$ and sulfur. For the balance gases $\mathrm{Ar}, \mathrm{He}$, and $\mathrm{N}_{2}$, the effluent gas mixture is the ternary 
system including $\mathrm{H}_{2}$ because sulfur is captured by the sulfur condenser. However, the mole fraction of balance gas at the reactor outlet is the same as that at the reactor inlet because $\mathrm{H}_{2} \mathrm{~S}$ dissociation is an equimolar gas phase reaction when the sulfur product is condensed. The outlet $\mathrm{H}_{2} \mathrm{~S}$ mole fraction can be determined from

$$
y_{o, H_{2} S}=K_{o} \cdot y_{i, B}
$$

where the subscript o represents the outlet gas. For the balance gas $\mathrm{H}_{2}$, the outlet $\mathrm{H}_{2} \mathrm{~S}$ mole fraction is

$$
y_{o, H_{2} S}=\frac{K_{o}}{K_{o}+1}
$$

Therefore, the conversion of $\mathrm{H}_{2} \mathrm{~S}$ in the PCDR is calculated from

$$
X_{\mathrm{H}_{2} \mathrm{~S}}=\frac{y_{i, \mathrm{H}_{2} \mathrm{~S}}-y_{o, \mathrm{H}_{2} \mathrm{~S}}}{y_{i, \mathrm{H}_{2} \mathrm{~S}}}
$$

Conversion rate and energy consumption of $\mathrm{H}_{2} \mathrm{~S}$ conversion are calculated from

$$
\begin{aligned}
& r=\frac{P F}{R T} \cdot y_{i, H_{2} S} \cdot X_{H_{2} S}\left(\mathrm{~mol} \cdot \mathrm{s}^{-1}\right) \\
& E n=\frac{W}{r} \cdot 1.0364 \times 10^{-5}\left(\mathrm{eV} \cdot \text { molecule }^{-1}\right)
\end{aligned}
$$

where $\mathrm{P}$ is the gas pressure, $\mathrm{F}$ is the gas flowrate, $\mathrm{T}$ is the temperature, and $\mathrm{R}$ is the gas constant.

For each parameter set, at least two experiments were performed to assure that the results are repeatable. All experimental data were reproducible within a $\pm 10 \%$ error limit, including the RGA and flow measurement uncertainties. Conversions based on either $\mathrm{H}_{2} \mathrm{~S}$ consumption or $\mathrm{H}_{2}$ production were similar, but the $\mathrm{H}_{2} \mathrm{~S}$ data provided higher accuracy. Mass balances could not be accurately calculated because not all sulfur was trapped in the condenser and some deposited on the reactor wall and the reactor outlet tube that could not be recovered for weighing. However, 
the amount of sulfur recovered was consistent with the reported conversions. Energy Dispersive Spectroscopy and X-ray diffraction were used to analyze the sulfur product.

\section{Results and Discussion}

Breakdown voltage of $\mathrm{H}_{2} \mathrm{~S}$ in the various balance gases. Gas breakdown voltage depends on the specific reactor configuration, especially the electrode configuration and structure. Breakdown voltages of many pure gases have been investigated in both uniform and non-uniform fields.(Blair, 1978) For uniform fields, the breakdown voltage usually follows Paschen's law, which states that breakdown voltage, $\mathrm{V}_{\mathrm{b}}$, is a function of nd only, where $\mathrm{n}$ is the gas number density (molecules $\mathrm{cm}^{-3}$ ) and $\mathrm{d}$ is the distance between the electrodes. For nonuniform fields, the breakdown voltage is a function of $\mathrm{nr}$, where $\mathrm{r}$ is the radius of curvature of the electrode surface at the point where the highest value of the electric field strength occurs (Blair, 1978). For the PCDR used in this work, $r$ is the radius of wire anode. For many pure gases in non-uniform fields, the breakdown voltage is proportional to $\mathrm{nr}$ at pressures higher than $0.5 \mathrm{bar}$ (Blair, 1978).

Gas breakdown can be detected by the discharge waveform recorder, shown in Figure 1. In addition, the audible discharge noise from PCDR can also be clearly heard when the corona discharge occurs. The breakdown voltage was determined by increasing the charge voltage in increments of $0.1 \mathrm{kV}$ from a low value at which no discharge occurs until the discharge is detected by both the discharge waveform recorder and the audible noise from the reactor. The measured breakdown voltages at different pressures for pure $\mathrm{Ar}, \mathrm{H}_{2}$, and $\mathrm{N}_{2}$ are shown in Figure 3. For this reactor, the anode radius, $\mathrm{r}$, is $0.0005 \mathrm{~m}$ and the inlet temperature is $300 \mathrm{~K}$. At these conditions, $\mathrm{nr}$ is proportional to gas pressure. The results presented in Figure 3 show that 
breakdown voltage is proportional to gas pressure, which is consistent with previous reports (Blair, 1978). Breakdown voltages of pure $\mathrm{N}_{2}$ measured at flowrates of $1.18 \times 10^{-4} \mathrm{SCM} \cdot \mathrm{s}^{-1}$ and $7.87 \times 10^{-6} \mathrm{SCM} \cdot \mathrm{s}^{-1}$ are almost the same, which indicates no effect of gas flowrate on breakdown voltage. In addition, pulse frequencies above $300 \mathrm{~Hz}$ do not affect breakdown voltage.

Breakdown of pure He occurred at any pressure from 0.8 to 5.0 bar at the lowest charge voltage of $6.9 \mathrm{kV}$ used in this work. However, breakdown of pure $\mathrm{H}_{2} \mathrm{~S}$ did not occur over the entire operation range for our reactor, which included pressures from 0.8 to 5.0 bar and charge voltages from 6.9 to $30 \mathrm{kV}$. These results combined with the results in Figure 3 indicate that the order of increasing breakdown voltage at constant pressure is: $\mathrm{He}<\mathrm{Ar}<\mathrm{H}_{2}<\mathrm{N}_{2}<\mathrm{H}_{2} \mathrm{~S}$, which is consistent with the order of increasing dielectric strength of these gases (dielectric strength of He: 0.15, Ar: 0.18, $\mathrm{H}_{2}:$ 0.50, $\mathrm{N}_{2}:$ 1.0, $\mathrm{H}_{2} \mathrm{~S}:$ 2.9) (Christophorou et al., 1987; Lide, 2003).

Because no corona was formed in pure $\mathrm{H}_{2} \mathrm{~S}$ at the maximum charge voltage ( $30 \mathrm{kV}$ ) with this reactor geometry, $\mathrm{H}_{2} \mathrm{~S}$ was mixed with another gas with lower dielectric strength to initiate electrical discharge. $\mathrm{He}, \mathrm{Ar}, \mathrm{N}_{2}$, and $\mathrm{H}_{2}$ were used as balance gases in this work because they do not produce byproducts in the corona.

As neither gas flowrate nor pulse frequency $(>300 \mathrm{~Hz}$ ) affect breakdown voltage, gas breakdown experiments were performed at a fixed gas flowrate of $1.18 \times 10^{-4} \mathrm{SCM} \cdot \mathrm{s}^{-1}$ and a pulse frequency of $400 \mathrm{~Hz}$. Figure 4 shows the breakdown voltage of $\mathrm{H}_{2} \mathrm{~S}$ in $\mathrm{H}_{2}$. At each fixed $\mathrm{H}_{2} \mathrm{~S}$ concentration, the breakdown voltage is proportional to total gas pressure, as shown in Figure 4(a), according to

$$
V_{b}=m_{i} \cdot P_{t}+n_{i}
$$


where $\mathrm{P}_{\mathrm{t}}$ is the total gas pressure in bar and $\mathrm{m}_{\mathrm{i}}$ and $\mathrm{n}_{\mathrm{i}}$ are the slope and the intercept at a specific $\mathrm{H}_{2} \mathrm{~S}$ mole fraction, respectively. Figure 4(b) shows the slope $m_{i}$ and the intercept $n_{i}$ as a function of $\mathrm{H}_{2} \mathrm{~S}$ mole fraction. These results show that the slope $\mathrm{m}_{\mathrm{i}}$ is proportional to $\mathrm{H}_{2} \mathrm{~S}$ mole fraction and the intercept $n_{i}$ is essentially constant. Therefore Equation (9) can be rewritten as

$$
V_{b}=\left(a_{1} \cdot y_{H_{2} S}+b_{1}\right) \cdot P_{t}+n=a_{1} \cdot P_{H_{2} S}+b_{1} \cdot\left(P_{H_{2} S}+P_{H_{2}}\right)+n
$$

where $\mathrm{a}_{1}$ and $\mathrm{b}_{1}$ are the slope and the intercept for the linear relationship of $\mathrm{m}_{\mathrm{i}}$ and $\mathrm{H}_{2} \mathrm{~S}$ mole fraction, respectively, and $\mathrm{P}_{\mathrm{H} 2 \mathrm{~S}}$ and $\mathrm{P}_{\mathrm{H}^{2}}$ are the partial pressures of $\mathrm{H}_{2} \mathrm{~S}$ and $\mathrm{H}_{2}$, respectively. Equation 10 can be further simplified as

$$
V_{b}=a_{2} \cdot P_{\mathrm{H}_{2} \mathrm{~S}}+b_{2} \cdot P_{\mathrm{H}_{2}}+c \quad\left(0.8 \mathrm{bar}<\mathrm{P}_{\mathrm{t}}<3.6 \mathrm{bar}\right)
$$

where $\mathrm{a}_{2}=\mathrm{a}_{1}+\mathrm{b}_{1}, \mathrm{~b}_{2}=\mathrm{b}_{1}$, and $\mathrm{c}=\mathrm{n}$. Equation (11) indicates that breakdown voltage is proportional to the partial pressures of the components in binary gas mixtures. Parameters $\mathrm{a}_{2}, \mathrm{~b}_{2}$, and c were obtained through a least-square regression analysis by application of Equation (11) to mixtures of $\mathrm{H}_{2} \mathrm{~S}$ in $\mathrm{Ar}, \mathrm{H}_{2} \mathrm{~S}$ in $\mathrm{He}, \mathrm{H}_{2} \mathrm{~S}$ in $\mathrm{N}_{2}$, and $\mathrm{H}_{2} \mathrm{~S}$ in $\mathrm{H}_{2}$,. The breakdown voltages $\left(\mathrm{V}_{\mathrm{b}}\right)$ are,

$$
\begin{array}{ll}
\mathrm{H}_{2} \mathrm{~S} \text { in Ar: } & \mathrm{V}_{\mathrm{b}}(\mathrm{kV})=22.2 \times \mathrm{P}_{\mathrm{H} 2 \mathrm{~S}}(\text { bar })+2.52 \times \mathrm{P}_{\mathrm{Ar}}(\text { bar })+6.48 \\
\mathrm{H}_{2} \mathrm{~S} \text { in He: } & \mathrm{V}_{\mathrm{b}}(\mathrm{kV})=16.2 \times \mathrm{P}_{\mathrm{H} 2 \mathrm{~S}}(\text { bar })+2.42 \times \mathrm{P}_{\mathrm{He}}(\text { bar })+3.35 \\
\mathrm{H}_{2} \mathrm{~S} \text { in } \mathrm{N}_{2}: & \mathrm{V}_{\mathrm{b}}(\mathrm{kV})=16.1 \times \mathrm{P}_{\mathrm{H} 2 \mathrm{~S}}(\text { bar })+6.44 \times \mathrm{P}_{\mathrm{N} 2}(\text { bar })+4.00 \\
\mathrm{H}_{2} \mathrm{~S} \text { in } \mathrm{H}_{2}: & \mathrm{V}_{\mathrm{b}}(\mathrm{kV})=15.2 \times \mathrm{P}_{\mathrm{H} 2 \mathrm{~S}}(\text { bar })+4.74 \times \mathrm{P}_{\mathrm{H}_{2}}(\text { bar })+2.70
\end{array}
$$

These correlations are valid for total absolute pressures between 0.8 bar and 3.6 bar and geometrically similar coaxial cylinder reactor systems. Figure 5 shows the experimental results and the fitted data using Equations 12(a)-(d). Most experimental data matched the fitted data, except for low concentrations ( $<4 \%)$ of $\mathrm{H}_{2} \mathrm{~S}$ in Ar. In this exceptional case, an increase in gas pressure causes the breakdown voltage to deviate from linearity at intermediate pressures before 
returning to linearity with a similar slope with a new intercept. Similar experimental results are obtained for $2 \% \mathrm{H}_{2} \mathrm{~S}$ in $\mathrm{Ar}$, but the reason for this exception is not yet clear.

$\mathbf{H}_{2} \mathrm{~S}$ conversion in various balance gases. Experiments on $\mathrm{H}_{2} \mathrm{~S}$ conversion in $\mathrm{Ar}, \mathrm{He}$, $\mathrm{N}_{2}$, and $\mathrm{H}_{2}$ were carried out at a fixed pulse frequency of $400 \mathrm{~Hz}$, charge voltage of $17 \mathrm{kV}$ (corresponding to power input of $110 \mathrm{~W}$ ), reactor pressure of $1.34 \mathrm{bar}$, and gas flowrate of 1.18 $\times 10^{-4} \mathrm{SCM} \cdot \mathrm{s}^{-1}$, corresponding to a gas residence time of $4.25 \mathrm{~s}$ in the reactor. As shown in Figure 5, the charge voltage of $17 \mathrm{kV}$ is higher than all breakdown voltages for gas mixtures of $\mathrm{H}_{2} \mathrm{~S}$ in $\mathrm{Ar}, \mathrm{H}_{2} \mathrm{~S}$ in $\mathrm{He}, \mathrm{H}_{2} \mathrm{~S}$ in $\mathrm{N}_{2}$, and $\mathrm{H}_{2} \mathrm{~S}$ in $\mathrm{H}_{2}$ at the total pressure of 1.34 bar, which confirmed that electrical discharges occur. Sulfur deposits in the sulfur condenser, as well as the reactor tube and outlet, further confirmed the active discharge. The presence of sulfur was confirmed by Energy Dispersive Spectroscopy. The first two principal peaks for orthorhombic $\alpha$-sulfur were observed in the X-ray diffraction data.

Figures 6(a)-(d) show $\mathrm{H}_{2} \mathrm{~S}$ conversion and rate data as a function of initial $\mathrm{H}_{2} \mathrm{~S}$ mole fraction. Similar trends of conversion and rate for gas mixtures of $\mathrm{H}_{2} \mathrm{~S}$ in $\mathrm{Ar}, \mathrm{H}_{2} \mathrm{~S}$ in $\mathrm{He}, \mathrm{H}_{2} \mathrm{~S}$ in $\mathrm{N}_{2}$, and $\mathrm{H}_{2} \mathrm{~S}$ in $\mathrm{H}_{2}$ were found. $\mathrm{H}_{2} \mathrm{~S}$ conversion decreases with increasing $\mathrm{H}_{2} \mathrm{~S}$ mole fraction, while the rate initially increases, reaches a maximum, and then decreases with increasing $\mathrm{H}_{2} \mathrm{~S}$ mole fraction.

There are four proposed mechanisms for $\mathrm{H}_{2} \mathrm{~S}$ conversion in nonthermal plasmas.

(I) Direct ionization of $\mathrm{H}_{2} \mathrm{~S}$ followed by dissociative neutralization (Ma et al., 2001; Helfritch, 1993):

$$
\begin{aligned}
& \mathrm{e}+\mathrm{H}_{2} \mathrm{~S} \rightarrow \mathrm{H}_{2} \mathrm{~S}^{+}+2 \mathrm{e} \\
& \mathrm{H}_{2} \mathrm{~S}^{+}+\mathrm{e} \rightarrow \mathrm{HS}+\mathrm{H}
\end{aligned}
$$


(II) Ionization of the balance gas (M), leading to charge transfer reaction, and subsequent dissociative recombination (Abolentsev et al., 1995):

$$
\begin{aligned}
& \mathrm{e}+\mathrm{M} \rightarrow \mathrm{M}^{+}+2 \mathrm{e} \\
& \mathrm{M}^{+}+\mathrm{H}_{2} \mathrm{~S} \rightarrow \mathrm{H}_{2} \mathrm{~S}^{+}+\mathrm{M} \\
& \mathrm{H}_{2} \mathrm{~S}^{+}+\mathrm{e} \rightarrow \mathrm{HS}+\mathrm{H}
\end{aligned}
$$

(III) Direct electron collision dissociation of $\mathrm{H}_{2} \mathrm{~S}$ :

$$
\mathrm{e}+\mathrm{H}_{2} \mathrm{~S} \rightarrow \mathrm{HS}+\mathrm{H}+\mathrm{e}
$$

(IV) Electron collision dissociation or excitation of the balance gas, which produces active species that contribute to $\mathrm{H}_{2} \mathrm{~S}$ dissociation:

$$
\begin{aligned}
& \mathrm{e}+\mathrm{M} \rightarrow \mathrm{M}^{*}+\mathrm{e} \\
& \mathrm{M}^{*}+\mathrm{H}_{2} \mathrm{~S} \rightarrow \mathrm{H}+\mathrm{HS}+\mathrm{M}
\end{aligned}
$$

Pathways (I) and (II) are unlikely for $\mathrm{H}_{2} \mathrm{~S}$ conversion for the following reasons:

(1) If pathway (I) is responsible for $\mathrm{H}_{2} \mathrm{~S}$ conversion, an increasing number of $\mathrm{H}_{2} \mathrm{~S}$ molecules should be ionized with increasing $\mathrm{H}_{2} \mathrm{~S}$ concentration, which should lead to increasing $\mathrm{H}_{2} \mathrm{~S}$ conversion rate with increasing $\mathrm{H}_{2} \mathrm{~S}$ concentration. This effect is not observed, as shown in Figure 6.

(2) If pathway (II) is responsible for $\mathrm{H}_{2} \mathrm{~S}$ conversion, then the ionization energies of the balance gases must be reasonably achieved within the reactor. However, this is not the case, as shown by the following example using He, which has an ionization energy of $24.6 \mathrm{eV} / \mathrm{He}$ or $2370 \mathrm{~kJ} / \mathrm{mol} \mathrm{He}$. At $110 \mathrm{~W}$ power input, if the whole energy input is assumed to be absorbed by He to form $\mathrm{He}^{+}$, the limiting conversion rate of $\mathrm{H}_{2} \mathrm{~S}$ is $46.3 \mu \mathrm{mol} / \mathrm{s}$. However, the results presented in Figure 6(b) show that most $\mathrm{H}_{2} \mathrm{~S}$ conversion rates are larger than $46.3 \mu \mathrm{mol} / \mathrm{s}$, which leaves pathway II unable to explain all of the observed $\mathrm{H}_{2} \mathrm{~S}$ conversion. 
(3) As shown in our recent investigation (Zhao et al., 2006a), the degree of ionization in the pulsed corona discharge is low. The major active species are produced through electron collision in the streamers, whose total volume is $10^{-4}-10^{-3}$ of the reactor volume (van Veldhuizen et al., 1996). In the streamer head, the concentration of ions (corresponding to the concentration of electrons) is around 15 ppm (Zhao et al., 2006a). If pathways (I) and (II) are responsible for $\mathrm{H}_{2} \mathrm{~S}$ conversion and all cations formed from reactions R1 and R3 contribute to $\mathrm{H}_{2} \mathrm{~S}$ conversion, the conversion of $\mathrm{H}_{2} \mathrm{~S}$ for initial $\mathrm{H}_{2} \mathrm{~S}$ mole fractions of 0.04 is $400 \mathrm{~Hz} \times 4.25 \mathrm{~s} \times 15 \mathrm{ppm} \times\left(10^{-4}-\right.$ $10^{-3}$ ) $/ 0.04=0.064-0.0064 \%$, which is at least two orders of magnitude lower than the $\mathrm{H}_{2} \mathrm{~S}$ conversions observed during the experiments, as shown in Figure 6. Therefore, the observed $\mathrm{H}_{2} \mathrm{~S}$ conversion solely through ionic reactions is not possible.

Conversion of $\mathrm{H}_{2} \mathrm{~S}$ through pathways (III) and (IV) can be supported by the following points:

(1) As demonstrated by Eliasson and Kogelschatz (1986, 1991), the concentration of radicals and excited states formed from electron collision reactions in the streamer head is at least two orders of magnitude higher than that of ions. In the streamer channel, the concentration of radicals and excited states formed from electron collision reactions is at least four orders of magnitude higher than that of ions. Most reactions are known to occur in the streamer channel (Zhao et al., 2006a). Therefore, if reactions R5-R7 contribute to $\mathrm{H}_{2} \mathrm{~S}$ conversion, the conversion of $\mathrm{H}_{2} \mathrm{~S}$ for initial mole fractions of 0.04 is $400 \mathrm{~Hz} \times 4.25 \mathrm{~s} \times\left(10^{4} \times 15 \mathrm{ppm}\right) \times\left(10^{-4}-10^{-3}\right) / 0.04=$ $\sim 64 \%$, which exceeds all the experimental results shown in Figure 6. However, this result is reasonable because the efficiency of such plasma reactions is less than $100 \%$.

(2) The occurrence of $\mathrm{H}_{2} \mathrm{~S}$ conversion through direct electron collision reaction R5 is suggested by the experimental data on $\mathrm{H}_{2} \mathrm{~S}$ conversion in He. Our previous study of Ar plasma 
in PCDR's (Zhao et al., 2006c) showed that the main active species formed during electron collision reactions with Ar are excited states and not cations. By analogy, the main active species contributing to $\mathrm{H}_{2} \mathrm{~S}$ conversion formed from electron collision reaction with He are assumed to be excited states of $\mathrm{He}$ and the contribution of ions to $\mathrm{H}_{2} \mathrm{~S}$ conversion in $\mathrm{He}$ is excluded from consideration. The first electronic excited state of $\mathrm{He}, \mathrm{He}\left(2^{3} \mathrm{~S}_{1}\right)$, has an excitation energy of $19.82 \mathrm{eV}$ (Prestage et al., 1985). If the excited states of He were the only active species contributing to $\mathrm{H}_{2} \mathrm{~S}$ (R6 and R7), the highest conversion rate of $\mathrm{H}_{2} \mathrm{~S}$ in He would be 110 $\mathrm{W} /(19.82 \mathrm{eV} \times 96.5 \mathrm{~kJ} / \mathrm{eV} \mathrm{mol})=57.5 \mu \mathrm{mol} / \mathrm{s}$. However, for concentrations of $\mathrm{H}_{2} \mathrm{~S}$ in He less than $12 \%$, the conversion rates of $\mathrm{H}_{2} \mathrm{~S}$ are all higher than $57.5 \mu \mathrm{mol} / \mathrm{s}$, which indicates that direct electron collision reaction of $\mathrm{H}_{2} \mathrm{~S}$ (R5) must contribute to $\mathrm{H}_{2} \mathrm{~S}$ conversion in addition to the He excited states.

The observed maximum in $\mathrm{H}_{2} \mathrm{~S}$ conversion rate in $\mathrm{Ar}, \mathrm{He}, \mathrm{N}_{2}$, and $\mathrm{H}_{2}$ with increasing mole fraction of $\mathrm{H}_{2} \mathrm{~S}$ can be explained through pathways (III) and (IV). For $\mathrm{H}_{2} \mathrm{~S}$ in Ar, previous investigation (Zhao et al., 2006c) has shown that the major product for direct electron collisions with $\mathrm{Ar}$ is the lowest excited state of $\operatorname{Ar}, \operatorname{Ar}\left({ }^{3} \mathrm{P}_{2}\right)$, which has an excitation energy of $11.55 \mathrm{eV}$.

$$
\mathrm{e}+\operatorname{Ar} \rightarrow \operatorname{Ar}\left({ }^{3} \mathrm{P}_{2}\right)+\mathrm{e}
$$

$\operatorname{Ar}\left({ }^{3} \mathrm{P}_{2}\right.$ ) contributes to $\mathrm{H}_{2} \mathrm{~S}$ dissociation and $\mathrm{H}_{2}$ dissociation as follows (Velazco et al., 1978; Gundel et al., 1976):

$$
\begin{array}{cc}
\operatorname{Ar}\left({ }^{3} \mathrm{P}_{2}\right)+\mathrm{H}_{2} \mathrm{~S} \rightarrow \mathrm{Ar}+\mathrm{H}+\mathrm{HS} & \mathrm{k}=5.18 \times 10^{14} \mathrm{~cm}^{3} \cdot \mathrm{mol}^{-1} \cdot \mathrm{s}^{-1} \\
\operatorname{Ar}\left({ }^{3} \mathrm{P}_{2}\right)+\mathrm{H}_{2} \rightarrow \mathrm{Ar}+\mathrm{H}+\mathrm{H} & \mathrm{k}=3.97 \times 10^{13} \mathrm{~cm}^{3} \cdot \mathrm{mol}^{-1} \cdot \mathrm{s}^{-1}
\end{array}
$$

Similarly, the following reactions contribute to $\mathrm{H}_{2} \mathrm{~S}$ conversion for $\mathrm{H}_{2} \mathrm{~S}$ in $\mathrm{He}$ (Bevsek et al., 1995; Someda et al., 1988; Yencha and Wu, 1978):

$$
\mathrm{e}+\mathrm{He} \rightarrow \mathrm{He}\left(2^{3} \mathrm{~S}_{1}\right)+\mathrm{e}
$$




$$
\begin{aligned}
& \mathrm{He}\left(2^{3} \mathrm{~S}_{1}\right)+\mathrm{H}_{2} \mathrm{~S} \rightarrow \mathrm{He}+\mathrm{H}+\mathrm{HS} \\
& \mathrm{He}\left(2^{3} \mathrm{~S}_{1}\right)+\mathrm{H}_{2} \rightarrow \mathrm{He}+\mathrm{H}+\mathrm{H}
\end{aligned}
$$

There are no reports of measured or calculated rate constants for reactions R12 and R13.

For $\mathrm{H}_{2} \mathrm{~S}$ in $\mathrm{N}_{2}$, the major products of electron collision reactions with $\mathrm{N}_{2}$ are $\mathrm{N}$ radicals and $\mathrm{N}_{2}(\mathrm{~A})$, the first electronic excited state of $\mathrm{N}_{2}$ (Zhao et al., 2004c).

$$
\begin{aligned}
& \mathrm{e}+\mathrm{N}_{2} \rightarrow \mathrm{N}+\mathrm{N}+\mathrm{e} \\
& \mathrm{e}+\mathrm{N}_{2} \rightarrow \mathrm{N}_{2}(\mathrm{~A})+\mathrm{e}
\end{aligned}
$$

Previous investigation (Zhao et al., 2005a) has shown that the rate of electron collision reaction R15 is about 7 times higher than that of R14. These active species react with $\mathrm{N}_{2}, \mathrm{H}_{2} \mathrm{~S}$, and $\mathrm{H}_{2}$ (Herron, 1999; Aleksandrov et al., 1994; Kossyi et al., 1992), as follows:

$$
\begin{array}{ll}
\mathrm{N}+\mathrm{H}_{2} \rightarrow \mathrm{NH}_{2} & \mathrm{k}=1.14 \times 10^{4} \mathrm{~cm}^{3} \cdot \mathrm{mol}^{-1} \cdot \mathrm{s}^{-1} \\
\mathrm{~N}+\mathrm{N} \rightarrow \mathrm{N}_{2} & \mathrm{k}=8.54 \times 10^{10} \mathrm{~cm}^{3} \cdot \mathrm{mol}^{-1} \cdot \mathrm{s}^{-1} \\
\mathrm{~N}_{2}(\mathrm{~A})+\mathrm{H}_{2} \rightarrow \mathrm{N}_{2}+2 \mathrm{H} & \mathrm{k}=2.11 \times 10^{9} \mathrm{~cm}^{3} \cdot \mathrm{mol}^{-1} \cdot \mathrm{s}^{-1} \\
\mathrm{~N}_{2}(\mathrm{~A})+\mathrm{H}_{2} \mathrm{~S} \rightarrow \mathrm{N}_{2}+\mathrm{H}+\mathrm{HS} & \mathrm{k}=1.81 \times 10^{14} \mathrm{~cm}^{3} \cdot \mathrm{mol}^{-1} \cdot \mathrm{s}^{-1}
\end{array}
$$

There are no reports of reaction of $\mathrm{H}_{2} \mathrm{~S}$ and $\mathrm{N}$. However, by analogy with the extremely low rate constant for the reaction of $\mathrm{N}$ with $\mathrm{H}_{2} \mathrm{O}\left(4 \times 10^{3} \mathrm{~cm}^{3} \cdot \mathrm{mol}^{-1} \cdot \mathrm{s}^{-1}\right.$ at $\left.1073 \mathrm{~K}\right)$ (Cohen and Westberg, 1991), we presume that $\mathrm{N}$ does not contribute significantly to $\mathrm{H}_{2} \mathrm{~S}$ conversion and that $\mathrm{N}$ radicals predominantly recombine to form $\mathrm{N}_{2}$ because the rate constant for this recombination reaction (R17) is about $8 \times 10^{6}$ higher than that of R16. In addition, no nitrogen containing byproducts, such as ammonia, were detected, which confirms that the only products of $\mathrm{H}_{2} \mathrm{~S}$ conversion in $\mathrm{N}_{2}$ are $\mathrm{H}_{2}$ and $\mathrm{S}$.

For $\mathrm{H}_{2} \mathrm{~S}$ in $\mathrm{H}_{2}$, the major product of electron collision with $\mathrm{H}_{2}$ is atomic $\mathrm{H}$ because the dissociation energy of $\mathrm{H}_{2}(4.4 \mathrm{eV})$ is far less than the excitation energy of the first excited state 17 
of $\mathrm{H}_{2}(11 \mathrm{eV})$ (Sharp, 1971), which results in all electronic excited states of $\mathrm{H}_{2}$ preferentially dissociating to $\mathrm{H}$ radicals:

$$
\mathrm{e}+\mathrm{H}_{2} \rightarrow \mathrm{H}+\mathrm{H}+\mathrm{e}
$$

Atomic $\mathrm{H}$ further contributes to $\mathrm{H}_{2} \mathrm{~S}$ conversion and formation in an autocatalytic manner through the following sequence of reactions (Peng et al., 1999; Stachnik and Molina, 1987; Schofield, 1973):

$$
\begin{array}{ll}
\mathrm{H}+\mathrm{H}_{2} \mathrm{~S} \rightarrow \mathrm{H}_{2}+\mathrm{HS} & \mathrm{k}=4.46 \times 10^{11} \mathrm{~cm}^{3} \cdot \mathrm{mol}^{-1} \cdot \mathrm{s}^{-1} \\
\mathrm{HS}+\mathrm{HS} \rightarrow \mathrm{H}_{2} \mathrm{~S}+\mathrm{S} & \mathrm{k}=2.41 \times 10^{13} \mathrm{~cm}^{3} \cdot \mathrm{mol}^{-1} \cdot \mathrm{s}^{-1} \\
\mathrm{~S}+\mathrm{HS} \rightarrow \mathrm{S}_{2}+\mathrm{H} & \mathrm{k}=2.41 \times 10^{13} \mathrm{~cm}^{3} \cdot \mathrm{mol}^{-1} \cdot \mathrm{s}^{-1}
\end{array}
$$

At low $\mathrm{H}_{2} \mathrm{~S}$ concentrations, most electrons collide with the balance gas, which suggests that pathway (IV) through reactions R6 and R7 is the major pathway for $\mathrm{H}_{2} \mathrm{~S}$ conversion. R8 and R9 are responsible for initiating $\mathrm{H}_{2} \mathrm{~S}$ conversion in Ar, R11 and R12 are responsible for initiating $\mathrm{H}_{2} \mathrm{~S}$ conversion in He, R15 and R19 are responsible for initiating $\mathrm{H}_{2} \mathrm{~S}$ conversion in $\mathrm{N}_{2}$, and R20 and R21 are responsible for initiating $\mathrm{H}_{2} \mathrm{~S}$ conversion in $\mathrm{H}_{2}$. With increasing $\mathrm{H}_{2} \mathrm{~S}$ concentration, the $\mathrm{H}_{2} \mathrm{~S}$ conversion rate increases because the rate of direct electron collision dissociation of $\mathrm{H}_{2} \mathrm{~S}$ (R5) increases. Moreover, the increasing rate of $\mathrm{H}_{2} \mathrm{~S}$ conversion through $\mathrm{R} 5$ is expected to be larger than the decreasing rate of $M^{*}$ formation through R6 (which further contributes to $\mathrm{H}_{2} \mathrm{~S}$ dissociation through R7) with increasing $\mathrm{H}_{2} \mathrm{~S}$ concentration because the dissociation energy of $\mathrm{H}_{2} \mathrm{~S}(3.4 \mathrm{eV})$ is far less than the excitation energy of $\operatorname{Ar}\left(11.55 \mathrm{eV}\right.$ for $\left.\operatorname{Ar}\left({ }^{3} \mathrm{P}_{2}\right)\right)$, He (19.82 eV for $\left.\mathrm{He}\left(2^{3} \mathrm{~S}_{1}\right)\right)$, or $\mathrm{N}_{2}\left(6.1 \mathrm{eV}\right.$ for $\left.\mathrm{N}_{2}(\mathrm{~A})\right)$, and the dissociation energy of $\mathrm{H}_{2}(4.4 \mathrm{eV})$. This explains the initial increase in $\mathrm{H}_{2} \mathrm{~S}$ conversion rate with increasing $\mathrm{H}_{2} \mathrm{~S}$ concentration, as shown in Figure 6. However, $\mathrm{H}_{2} \mathrm{~S}$ is electronegative (Christophorou et al., 1987). The presence of an electronegative gas as a reactant reduces the discharge current in the reactor by capturing 
electrons. Thus, the electron concentration during discharge is reduced due to the high electron affinity of $\mathrm{H}_{2} \mathrm{~S}$, which results in a deceasing rate of electron collision reactions, as observed previously (Zhao et al., 2005d,e). With increasing $\mathrm{H}_{2} \mathrm{~S}$ concentration, the electronegative effect of $\mathrm{H}_{2} \mathrm{~S}$ becomes more prominent and finally results in decreasing rates of electron collision reactions (R5 and R6). These effects explain the maxima and subsequent decrease of $\mathrm{H}_{2} \mathrm{~S}$ conversion rates with increasing $\mathrm{H}_{2} \mathrm{~S}$ concentration shown in Figure 6 .

Figure 7 shows energy consumption during $\mathrm{H}_{2} \mathrm{~S}$ conversion as a function of $\mathrm{H}_{2} \mathrm{~S}$ mole fraction in the four balance gases. The energy consumption of $\mathrm{H}_{2} \mathrm{~S}$ conversion initially decreases, reaches a minimum, and increases with increasing $\mathrm{H}_{2} \mathrm{~S}$ mole fraction, which is consistent with the trend of $\mathrm{H}_{2} \mathrm{~S}$ conversion rate shown in Figure 6. Energy consumption during $\mathrm{H}_{2} \mathrm{~S}$ conversion in $\mathrm{H}_{2}$ is higher than in $\mathrm{N}_{2}$ because the cross sectional area of molecular $\mathrm{H}_{2}$ is 1.86 times smaller than that of $\mathrm{N}_{2}$ (as shown by the respective effective molecular radius of 1.35 versus $1.84 \AA$ ) (Daubert and Danner, 1997), which causes a lower rate of electron collision reactions with $\mathrm{H}_{2}$ compared to $\mathrm{N}_{2}$ and results in more energy dissipation in $\mathrm{H}_{2}$ compared to $\mathrm{N}_{2}$. Energy consumption during $\mathrm{H}_{2} \mathrm{~S}$ conversion in $\mathrm{Ar}$ and $\mathrm{He}$ are the lowest of the tested gases and similar in magnitude.

Energy consumption during $\mathrm{H}_{2} \mathrm{~S}$ conversion in monatomic balance gases is far lower than in diatomic balances gas, which can be explained through analysis of electron collision processes for $\mathrm{H}_{2} \mathrm{~S}$ in the monatomic and diatomic balance gases. When an energetic electron collides with an atomic molecule, the electron predominantly experiences elastic collision without energy loss if the electron energy is less than the excitation energy of target atom. The electron is then further accelerated in the electric field and hence gains more energy. If the electron collides with $\mathrm{H}_{2} \mathrm{~S}$ in the next collision, $\mathrm{H}_{2} \mathrm{~S}$ can be dissociated easily because the electron has already 
experienced two accelerations over approximately two mean free path lengths of the gas molecules. When an energetic electron collides with a diatomic molecule, the electron can lose energy through the many energy levels available to diatomic molecules, including excitation, rotation, vibration, and dissociation, depending on the electron energy. For example, an energetic electron would be deactivated by contributing its energy to rotation and vibration of the diatomic molecule if the electron energy is less than excitation energy or dissociation energy. This implies that electrons cannot gain energy as efficiently in a diatomic balance gas compared to monatomic gases. The electron energy in atomic gases can be used more efficiently because there are no paths for energy loss to rotation and vibration. Therefore, energy efficiency of $\mathrm{H}_{2} \mathrm{~S}$ conversion in atomic balance gases is expected to be higher than that in diatomic balance gases, as observed in Figure 7.

The results in Figure 7 show that the lowest energy consumption (highest efficiency) of $\mathrm{H}_{2} \mathrm{~S}$ conversion is $17 \mathrm{eV} / \mathrm{H}_{2} \mathrm{~S}$. This value is lower than the energy consumption reported in all previous investigations (Helfritch, 1993; Ruan et al., 1999; Abolentsev et al., 1995; Ma et al., 2001; Traus and Suhr, 1992; Traus et al., 1993; Dalaine et al., 1998a,b), except in microwave discharges at sub-atmospheric pressures $\left(\sim 4.5 \mathrm{eV} / \mathrm{H}_{2} \mathrm{~S}\right)$ (Cox et al., 1998). This result confirms that pulsed corona discharges are more efficient than other types and that relatively low energy consumption can be obtained at high pressures and $\mathrm{H}_{2} \mathrm{~S}$ concentrations. However, most hydrogen produced industrially by steam reforming of methane and other light alkanes has an energy consumption of $3.92 \mathrm{eV} / \mathrm{H}_{2}$ (Cox et al., 1998), which is a factor of 4 less than the best (lowest) experimental values for energy consumption during $\mathrm{H}_{2} \mathrm{~S}$ conversion found during the present investigation. Thus, further improvements in plasma efficiency must be achieved before plasma processes can compete with current hydrogen production methods. 


\section{Conclusions}

Breakdown voltages of $\mathrm{H}_{2} \mathrm{~S}$ in four balance gases (Ar, $\mathrm{He}, \mathrm{N}_{2}$ and $\mathrm{H}_{2}$ ) measured at different $\mathrm{H}_{2} \mathrm{~S}$ concentrations and pressures are proportional to the partial pressures of $\mathrm{H}_{2} \mathrm{~S}$ and the respective balance gas. $\mathrm{H}_{2} \mathrm{~S}$ conversion rates and energy efficiencies depend on the balance gas and $\mathrm{H}_{2} \mathrm{~S}$ inlet concentrations. With increasing $\mathrm{H}_{2} \mathrm{~S}$ concentrations, $\mathrm{H}_{2} \mathrm{~S}$ conversion rates initially increase, reach a maximum, and then decrease. $\mathrm{H}_{2} \mathrm{~S}$ conversion in atomic balance gases, such as $\mathrm{Ar}$ and $\mathrm{He}$, is more efficient than that in diatomic balance gases, such as $\mathrm{N}_{2}$ and $\mathrm{H}_{2}$. These observations can be explained by reaction mechanisms that involve electron collision reactions either with $\mathrm{H}_{2} \mathrm{~S}$ that cause direct dissociation or with the balance gas to produce active species in electronic exited states that then relax by dissociating $\mathrm{H}_{2} \mathrm{~S}$. The results show that nonthermal plasmas are effective for dissociating $\mathrm{H}_{2} \mathrm{~S}$ into hydrogen and sulfur, but further increases in energy efficiency are necessary.

\section{Acknowledgments}

This work was supported by the Department of Energy (DE-FC26-03NT41963) and the University of Wyoming Research Office. The authors gratefully acknowledge experimental assistance provided by Mr. R. Borgialli. 


\section{Literature Cited}

Abolentsev, V.A., Korobtsev, S.V., Medvedev, D.D., Potapkin, B.V., Rusanon, V.D., Fridman, A.A., Shiryaevskii, V.L., 1995. Pulsed "wet" discharge as an effective means of gas purification from $\mathrm{H}_{2} \mathrm{~S}$ and organosulfur impurities. High Energy Chemistry 29, 353.

Aleksandrov, E.N., Basevich, V.Y., Vedeneev, V.I., 1994. The elementary act of the reaction of nitrogen atoms with hydrogen in a gas phase. Khimicheskaya Fizika 13, 90.

Asisov, R.I., Vakar, A.K., Gutsol, A.F., Givotov, V.K., Krasheninnikov, E.G., Krotov, M.F., Rusanov, V.D., Fridman, A.A., Sholin, G.V., 1985. Plasmachemical methods of energy carrier production. International Journal of Hydrogen Energy 10, 475.

Averin, V.G., Potapkin, V.B., Rusanon, V.D., Fridman, A.A., Shiryaevskii, V.L., 1996. Dissociation of hydrogen sulfide molecules in a pulsed electric discharge. High Energy Chemistry 30, 125.

Bagautdinov, A.Z., Jivotov, V.K., Eremenko, J.I., Kalachev, I.A., Kozbagarov, A.I., Konstantinov, E.I., Musinov, S.A., Overchuk, K.I., Rusanon, V.D., Zoller, V.A., 1998. Plasmachemical hydrogen production from natural gases containing hydrogen sulfide. Hydrogen Energy Progress XII, Proceedings of the World Hydrogen Energy Conference, 12th, Buenos Aires, Argentina, 1, 683.

Bagautdinov, A.Z., Jivotov, V.K., Eremenko, J.I., Kalachev, I.A., Musinov, S.A., Pampushka, A.M., Rusanon, V.D., Zoller, V.A., 1993a. Natural hydrogen sulfide $\left(\mathrm{H}_{2} \mathrm{~S}\right)$ - source of hydrogen (plasma chemical dissociation). Frontier Science Series 7, 123.

Bagautdinov, A.Z., Zhivotov, V.K., Kalachev, I.A., Musinov, S.A., Pampushka, A.M., Rusanov, V.D., Tsoller, V.A., 1993b. Investigations of the Radial Distributions of Gas Flows in a High Power Microwave Discharge. High Energy Chemistry 27, 305.

Bagautdinov, A.Z., Jivotov, V.K., Eremenko, J.I., Kalachev, I.A., Musinov, S.A., Potapkin, B.V., Pampushka, A.M., Rusanov, V.D., Strelkova, M.I., Fridman, A.A., Zoller, V.A., 1995. Plasma chemical production of hydrogen from $\mathrm{H}_{2} \mathrm{~S}$-containing gases in MCW discharge. International Journal of Hydrogen Energy 20, 193.

Bagautdinov, A.Z., Zhivotov, V.K., Musinov, S.V., Pampushka, A.M., Rusanov, V.D., Zoller, V.A., Epp, P.Y., 1992. Physicochemical processes during the dissociation of a hydrogen sulfidecarbon dioxide mixture in a microwave discharge. Khimiya Vysokikh Energii 26, 69.

Bevsek, H.M., Dunlavy, D.C., Siska, P.E., 1995. Nascent vibrational populations in $\operatorname{He}^{*}(2$ $\left.{ }^{1,3} \mathrm{~S}\right)+\mathrm{H}_{2}, \mathrm{HD}, \mathrm{D}_{2}$ Penning ionization from electron spectroscopy in crossed supersonic molecular beams. Journal of Chemical Physics 102, 133.

Blair, D.T.A., 1978. Breakdown Voltage Characteristics. In Electrical Breakdown of gases, Meek, J.M., Craggs, J.D., Eds., John Wiley \& Sons: New York, 1978, p533.

22 
Christophorou, L.G., Rodrigo, H., Marode, E., Bastien, F., 1987. Isotopic dependences of the dielectric strength of gases - new observations, classification, and possible origins. Journal of Physics D: Applied Physics 20, 1031.

Cohen, N., Westberg, K.R., 1991. Chemical kinetic data sheets for high-temperature reactions. Part II. Journal of Physical and Chemical Reference Data 20, 1211.

Cox, B.G., Clarke, P.F., Pruden, B.B., 1998. Economics of thermal dissociation of $\mathrm{H}_{2} \mathrm{~S}$ to produce hydrogen. International Journal of Hydrogen Energy 23, 531.

Dalaine, V., Cormier, J.M., Lefaucheux, P., 1998a. A gliding discharge applied to $\mathrm{H}_{2} \mathrm{~S}$ destruction. Journal of Applied Physics 83, 2435.

Dalaine, V., Cormier, J.M., Pellerin, S., Lefaucheux, P., 1998b. $\mathrm{H}_{2} \mathrm{~S}$ destruction in $50 \mathrm{~Hz}$ and 25 kHz gliding arc reactors. Journal of Applied Physics 84, 1215.

Daubert, T.E., Danner, R.P., 1997. Physical and Thermodynamic Properties of Pure Chemicals, Data Compilation; Taylor \& Francis, Washington, DC.

Eliasson, B., Kogelschatz, U., 1986. Electron Impact Dissociation in Oxygen. Journal of Physics B 19, 1241.

Eliasson, B., Kogelschatz, U., 1991. Modeling and Applications of Silent Discharge Plasmas. IEEE Transactions on Plasma Science 19, 309.

Gundel, L.A., Setser, D.W., Clyne, M.A.A., Coxon, J.A., Nip, W., 1976. Rate constants for specific product channels from $\operatorname{Ar}\left({ }^{3} \mathrm{P}_{2,0}\right)$ reactions and spectrometer calibration in the vacuum ultraviolet. Journal of Chemical Physics 64, 4390.

Helfritch, D.J., 1993. Pulsed corona discharge for hydrogen sulfide decomposition. IEEE Transactions on Industry Applications 29, 882.

Herron, J.T., 1999. Evaluated Chemical Kinetics Data for Reactions of $\mathrm{N}\left({ }^{2} \mathrm{D}\right), \mathrm{N}\left({ }^{2} \mathrm{P}\right)$, and $\mathrm{N}_{2}\left(\mathrm{~A}^{3} \Sigma_{\mathrm{u}}{ }^{+}\right)$in the Gas Phase. Journal of Physical and Chemical Reference Data 28, 1453.

Kaloidas, V.E., Papayannakos, N.G., 1987. Hydrogen production from the decomposition of hydrogen sulfide. Equilibrium studies on the system $\mathrm{H}_{2} \mathrm{~S} / \mathrm{H}_{2} / \mathrm{S}_{\mathrm{i}},(\mathrm{i}=1, \ldots, 8)$ in the gas phase. International Journal of Hydrogen Energy 12, 403.

Kossyi, I.A., Kostinsky, A.Y., Matveyev, A.A., Silakov, V.P., 1992. Kinetic Scheme of the Non-equilibrium Discharge in Nitrogen-Oxygen Mixtures. Plasma Sources Science \& Technology 1, 207.

Lide, D.R., 2003. CRC Handbook of Chemistry and Physics; CRC Press: Boca Raton, Florida. 
Ma, H., Chen, P., Ruan, R., 2001. $\mathrm{H}_{2} \mathrm{~S}$ and $\mathrm{NH}_{3}$ removal by silent discharge plasma and ozone combo-system. Plasma Chemistry and Plasma Processing 21, 611.

Peng, J., Hu, X., Marshall, P., 1999. Experimental and ab Initio Investigations of the Kinetics of the Reaction of $\mathrm{H}$ Atoms with $\mathrm{H}_{2} \mathrm{~S}$. Journal of Physical Chemistry A 103, 5307.

Prestage, J.D., Johnson, C.E., Hinds, E.A., Pichanick, F.M.J., 1985. Precise study of hyperfine structure in the $2^{3} \mathrm{P}$ state of ${ }^{3} \mathrm{He}$. Physical Review A 32, 2712.

Ruan, R.R., Han, W., Ning, A., Chen, P.L., Goodrich, P.R., Zhang, R., 1999. Treatment of odorous and hazardous gases using non-thermal plasma. Journal of Advanced Oxidation Technologies 4, 328.

Schofield, K., 1973. Evaluated chemical kinetic rate constants for various gas phase reactions. Journal of Physical and Chemical Reference Data 2, 25.

Sharp, T.E., 1971. Potential-Energy Curves for Molecular Hydrogen and Its Ions. Atomic Data 2, 119.

Someda, K., Kondow, T., Kuchitsu, K., 1988. n-Distributions of atomic hydrogen(n) produced from water, water-d2, and hydrogen sulfide in collision with metastable helium atoms. Journal of Physical Chemistry 92, 6541.

Stachnik, R.A., Molina, M.J., 1987. Kinetics of the reactions of mercapto radicals with $\mathrm{NO}_{2}$ and $\mathrm{O}_{2}$. Journal of Physical Chemistry 91, 4603.

Traus, I., Suhr, H., 1992. Hydrogen sulfide dissociation in ozonizer discharges and operation of ozonizers at elevated temperatures. Plasma Chemistry and Plasma Processing 12, 275.

Traus, I., Suhr, H., Harry, J.E., Evans, D.R., 1993. Application of a rotating high-pressure glow discharge for the dissociation of hydrogen sulfide. Plasma Chemistry and Plasma Processing 13, 77.

van Veldhuizen, E.M., Rutgers, W.R., Bityurin, V.A., 1996. Energy efficiency of NO removal by pulsed corona discharges. Plasma Chemistry and Plasma Processing 16, 227.

Velazco, J.E., Kolts, J.H., Setser, D.W., 1978. Rate constants and quenching mechanisms for the metastable states of argon, krypton, and xenon. Journal of Chemical Physics 69, 4357.

Watson, J.T., 1997. Introduction to Mass Spectrometry, 3rd ed.; Lippincott-Raven, Philadelphia.

Wiseman, N., Douglas, W.J.M., 1972. Oxidation of hydrogen sulfide in a corona discharge. AIChE Symposium Series 68, 297.

Yao, S., Nakayama, A., Suzuki, E., 2001. Acetylene and hydrogen from pulsed plasma conversion of methane. Catalysis Today 71, 219. 
Yencha, A.J., Wu, K.T., 1978. Energy transfer processes in reactions of $\mathrm{He}\left(2^{3} \mathrm{~S}\right)$ with triatomic molecules. II. $\mathrm{H}_{2} \mathrm{O}$ and $\mathrm{H}_{2} \mathrm{~S}$. Chemical Physics 32, 247.

Zaman, J., Chakma, A., 1995. Production of hydrogen and sulfur from hydrogen sulfide. Fuel Processing Technology 41, 159.

Zhao, G.-B., Hu, X., Plumb, O.A., Radosz, M., 2004a. Energy Consumption and Optimal Reactor Configuration for Nonthermal Plasma Conversion of $\mathrm{N}_{2} \mathrm{O}$ in Nitrogen and $\mathrm{N}_{2} \mathrm{O}$ in Argon. Energy \& Fuels 18, 1522.

Zhao, G.-B., Hu, X., Yeung, M.C., Plumb, O.A., Radosz, M., 2004b. Nonthermal Plasma Reactions of Dilute Nitrogen Oxide Mixtures: $\mathrm{NO}_{\mathrm{x}}$ in Nitrogen. Industrial \& Engineering Chemistry Research 43, 2315.

Zhao, G.-B., Hu, X., Argyle, M.D., Radosz, M., 2004c. N Atom Radicals and $\mathrm{N}_{2}\left(\mathrm{~A}^{3} \Sigma_{\mathrm{u}}^{+}\right)$Found to be Responsible for Nitrogen Oxides Conversion in Non-thermal Nitrogen Plasma. Industrial \& Engineering Chemistry Research 43, 5077.

Zhao, G.-B., Garikipati, S.V.B.J., Hu, X., Argyle, M.D., Radosz, M., 2005a. The Effect of Gas Pressure on NO Conversion Energy Efficiency in Nonthermal Nitrogen Plasma. Chemical Engineering Science 60, 1927.

Zhao, G.-B., Garikipati, S.V.B.J., Hu, X., Argyle, M.D., Radosz, M., 2005b. Effect of Reactor Configuration on Nitric Oxide Conversion in Nitrogen Plasma. AIChE J 51, 1813.

Zhao, G.-B., Hu, X., Argyle, M. D., Radosz, M., 2005b. Effect of $\mathrm{CO}_{2}$ on Nonthermal-Plasma Reactions of Nitrogen Oxides in $\mathrm{N}_{2}$. Part I: ppm-level Concentrations. Industrial \& Engineering Chemistry Research 44, 3925.

Zhao, G.-B., Garikipati, S.V.B.J., Hu, X., Argyle, M.D., Radosz, M., 2005d. Effect of Oxygen on Nonthermal-Plasma Reactions of Nitrogen Oxides in Ntrogen. AIChE J 51, 1800.

Zhao, G.-B., Hu, X., Argyle, M. D., Radosz, M., 2005e. Effect of $\mathrm{CO}_{2}$ on Nonthermal-Plasma Reactions of Nitrogen Oxides in $\mathrm{N}_{2}$. Part II: Percent-level Concentrations. Industrial \& Engineering Chemistry Research 44, 3935.

Zhao, G.-B., Argyle, M.D., Radosz, M., 2006a. Optical Emission Study of Nonthermal Plasma Confirms Reaction Mechanisms Involving Neutral Rather than Charged Species. Journal of Applied Physics (in press).

Zhao, G.-B., John, S., Zhang, J.-J., Wang, L., Mukhnahallipatna, S., Hamann, J., Ackerman, J., Argyle, M.D., Plumb, O.A., 2006b. Methane Conversion in Pulsed Corona Discharge Reactors. Journal of Chemical Engineering 125, 67. 
Zhao, G.-B., Argyle, M.D., Radosz, M., 2006c. Effect of CO on Conversion of NO and $\mathrm{N}_{2} \mathrm{O}$ in Nonthermal Argon Plasma. Journal of Applied Physics 99, 113302/1. 


\section{Figure Captions}

Figure 1. Experimental setup

1. $\mathrm{H}_{2} \mathrm{~S}$ gas cylinder, 2. balance gas cylinder (Ar, $\mathrm{He}, \mathrm{N}_{2}, \mathrm{H}_{2}$ ), 3. mass flow controller, 4. pressure gauge, 5 . pulsed corona discharge reactor, 6. sulfur condenser, 7 . valve, 8. RGA, 9. data collection computer, 10. thyratron switch, 11. HV power supply and control circuit, 12. discharge waveform recorder.

Figure 2. Calibration plot for $\mathrm{H}_{2} \mathrm{~S}$ relative to the balance gas used as an internal standard.

Figure 3. Breakdown voltage of pure gases as a function of pressure.

(ם): Ar at $1.18 \times 10^{-4} \mathrm{SCM} \cdot \mathrm{s}^{-1}$ and $400 \mathrm{~Hz} ;(\mathbf{O}): \mathrm{H}_{2}$ at $1.18 \times 10^{-4} \mathrm{SCM} \cdot \mathrm{s}^{-1}$ and 400 $\mathrm{Hz} ;(\boldsymbol{\Delta}): \mathrm{N}_{2}$ at $1.18 \times 10^{-4} \mathrm{SCM} \cdot \mathrm{s}^{-1}$ and $400 \mathrm{~Hz} ;(\boldsymbol{\nabla}): \mathrm{N}_{2}$ at $7.87 \times 10^{-6} \mathrm{SCM} \cdot \mathrm{s}^{-1}$ and $400 \mathrm{~Hz}$

Figure 4. Breakdown voltage of $\mathrm{H}_{2} \mathrm{~S}$ in $\mathrm{H}_{2}$.

(a) Breakdown voltage as a function of total gas pressure. Experimental data: $(\square)$ : 4\% $\mathrm{H}_{2} \mathrm{~S},(\bigcirc): 8 \% \mathrm{H}_{2} \mathrm{~S},(\triangle): 12 \% \mathrm{H}_{2} \mathrm{~S},(\nabla): 16 \% \mathrm{H}_{2} \mathrm{~S}$, $(+): 25 \% \mathrm{H}_{2} \mathrm{~S}$; linear regression: (-): $4 \% \mathrm{H}_{2} \mathrm{~S},(--)$ : $8 \% \mathrm{H}_{2} \mathrm{~S},(\cdots)$ : $12 \% \mathrm{H}_{2} \mathrm{~S},(-\cdot-)$ : $16 \% \mathrm{H}_{2} \mathrm{~S},(---)$ : $25 \% \mathrm{H}_{2} \mathrm{~S}$. (b) Slope and intercept from linear regression in (a) as a function of $\mathrm{H}_{2} \mathrm{~S}$ mole fraction. (ם): slope $\mathrm{m}_{\mathrm{i}} ;(\boldsymbol{\Delta})$ : intercept $\mathrm{n}_{\mathrm{i}}$.

Figure 5. Breakdown voltage as a function of total gas pressure. (a) $\mathrm{H}_{2} \mathrm{~S}$ in Ar; (b) $\mathrm{H}_{2} \mathrm{~S}$ in He; (c) $\mathrm{H}_{2} \mathrm{~S}$ in $\mathrm{N}_{2}$; (d) $\mathrm{H}_{2} \mathrm{~S}$ in $\mathrm{H}_{2}$ Experimental data: $(\square): 4 \% \mathrm{H}_{2} \mathrm{~S} ;(\bigcirc): 8 \% \mathrm{H}_{2} \mathrm{~S} ;(\triangle)$ : $12 \% \mathrm{H}_{2} \mathrm{~S} ;(\nabla): 16 \% \mathrm{H}_{2} \mathrm{~S}$;

$(\diamond): 20 \% \mathrm{H}_{2} \mathrm{~S} ;(+): 25 \% \mathrm{H}_{2} \mathrm{~S} ;(\times): 30 \% \mathrm{H}_{2} \mathrm{~S}$

Calculated data: $(-)$ : $4 \% \mathrm{H}_{2} \mathrm{~S} ;(--): 8 \% \mathrm{H}_{2} \mathrm{~S} ;(\cdots)$ : $12 \% \mathrm{H}_{2} \mathrm{~S} ;(-\cdot-)$ : $16 \% \mathrm{H}_{2} \mathrm{~S}$; $(-\cdots-): 20 \% \mathrm{H}_{2} \mathrm{~S} ;(---): 25 \% \mathrm{H}_{2} \mathrm{~S} ;(-\cdot-): 30 \% \mathrm{H}_{2} \mathrm{~S}$

Figure 6. $\mathrm{H}_{2} \mathrm{~S}$ conversion and conversion rate as a function of $\mathrm{H}_{2} \mathrm{~S}$ mole fraction in different balance gases. $(\square)$ : conversion, $(\mathbf{\square})$ : conversion rate

Figure 7. Energy consumption of $\mathrm{H}_{2} \mathrm{~S}$ conversion as a function of $\mathrm{H}_{2} \mathrm{~S}$ mole fraction in different balance gases. (ם): $\mathrm{H}_{2} \mathrm{~S}$ in $\mathrm{Ar},(\square): \mathrm{H}_{2} \mathrm{~S}$ in $\mathrm{He},(\boldsymbol{\Delta}): \mathrm{H}_{2} \mathrm{~S}$ in $\mathrm{N}_{2},(\triangle): \mathrm{H}_{2} \mathrm{~S}$ in $\mathrm{H}_{2}$ 


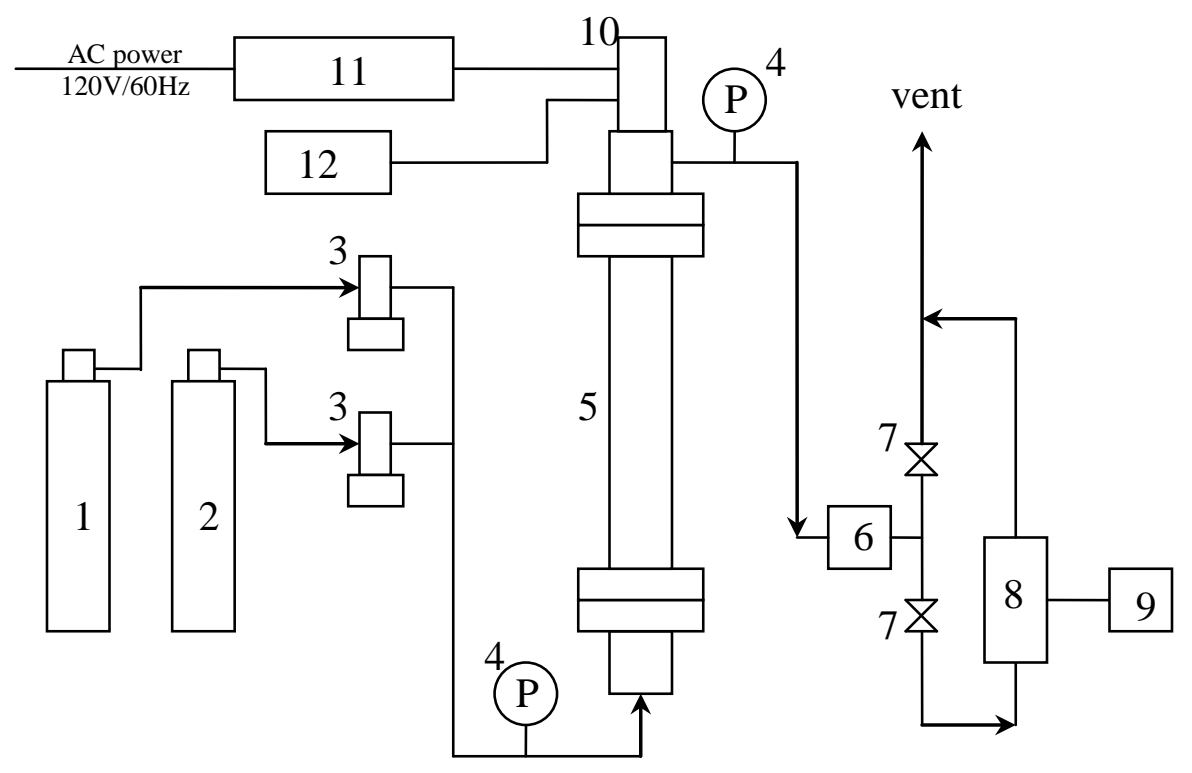

Figure 1. Experimental setup

1. $\mathrm{H}_{2} \mathrm{~S}$ gas cylinder, 2. balance gas cylinder ( $\mathrm{Ar}, \mathrm{He}, \mathrm{N}_{2}, \mathrm{H}_{2}$ ), 3. mass flow controller, 4. pressure gauge, 5. pulsed corona discharge reactor, 6. sulfur condenser, 7. valve, 8. RGA, 9. data collection computer, 10. thyratron switch, 11. HV power supply and control circuit, 12. discharge waveform recorder. 

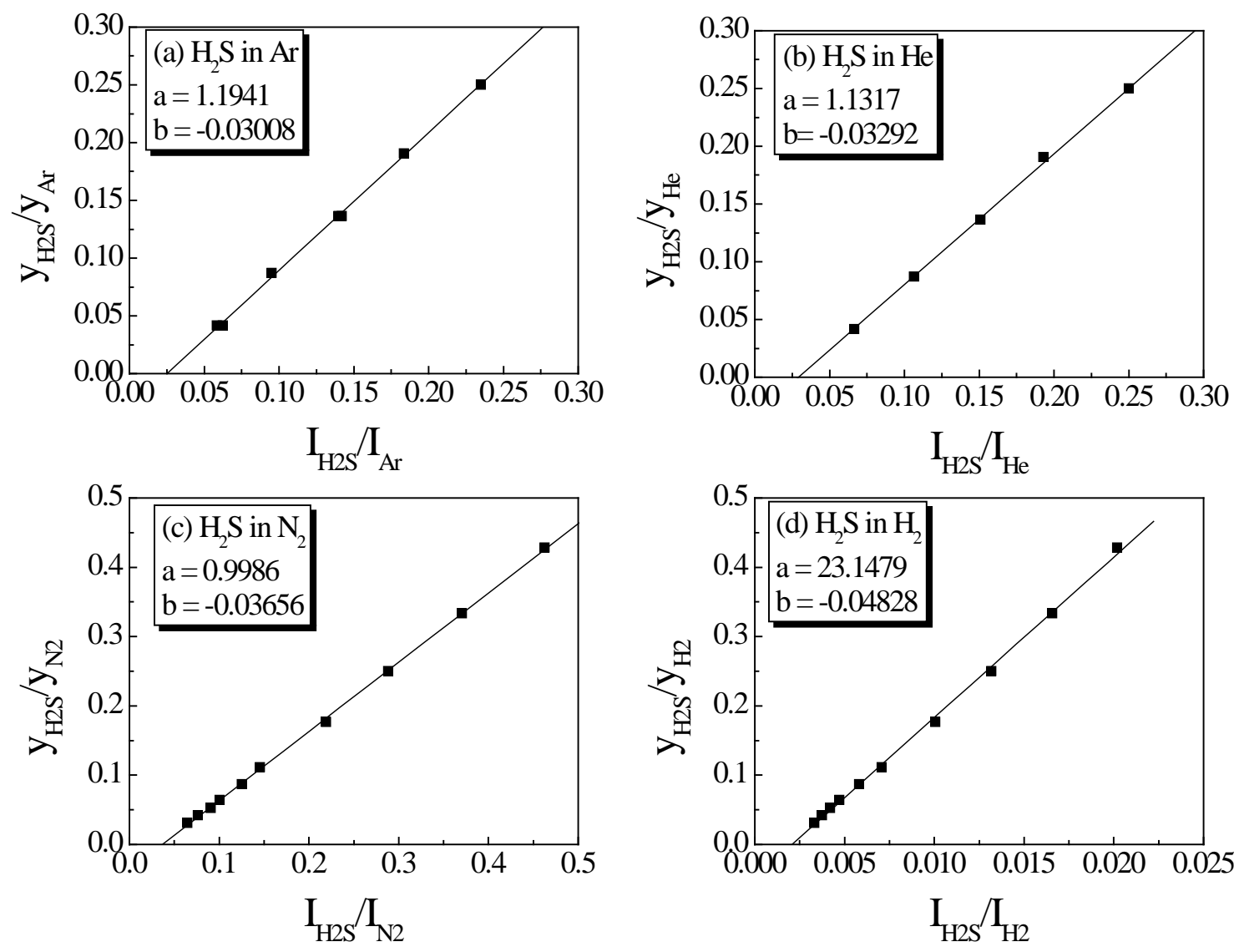

Figure 2. Calibration plots for $\mathrm{H}_{2} \mathrm{~S}$ relative to the balance gas used as an internal standard. 


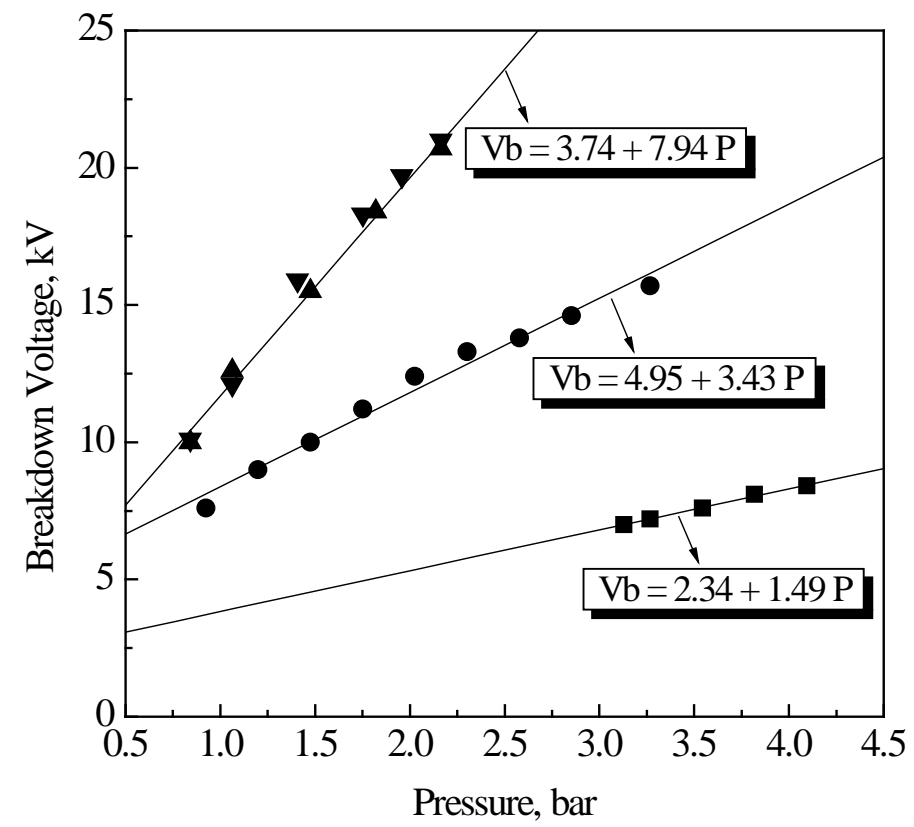

Figure 3. Breakdown voltage of pure gases as a function of pressure.

(ם): Ar at $1.18 \times 10^{-4} \mathrm{SCM} \cdot \mathrm{s}^{-1}$ and $400 \mathrm{~Hz} ;(\boldsymbol{)}): \mathrm{H}_{2}$ at $1.18 \times 10^{-4} \mathrm{SCM} \cdot \mathrm{s}^{-1}$ and $400 \mathrm{~Hz}$; (A): $\mathrm{N}_{2}$ at $1.18 \times 10^{-4} \mathrm{SCM} \cdot \mathrm{s}^{-1}$ and $400 \mathrm{~Hz} ;(\boldsymbol{\nabla}): \mathrm{N}_{2}$ at $7.87 \times 10^{-6} \mathrm{SCM} \cdot \mathrm{s}^{-1}$ and $400 \mathrm{~Hz}$
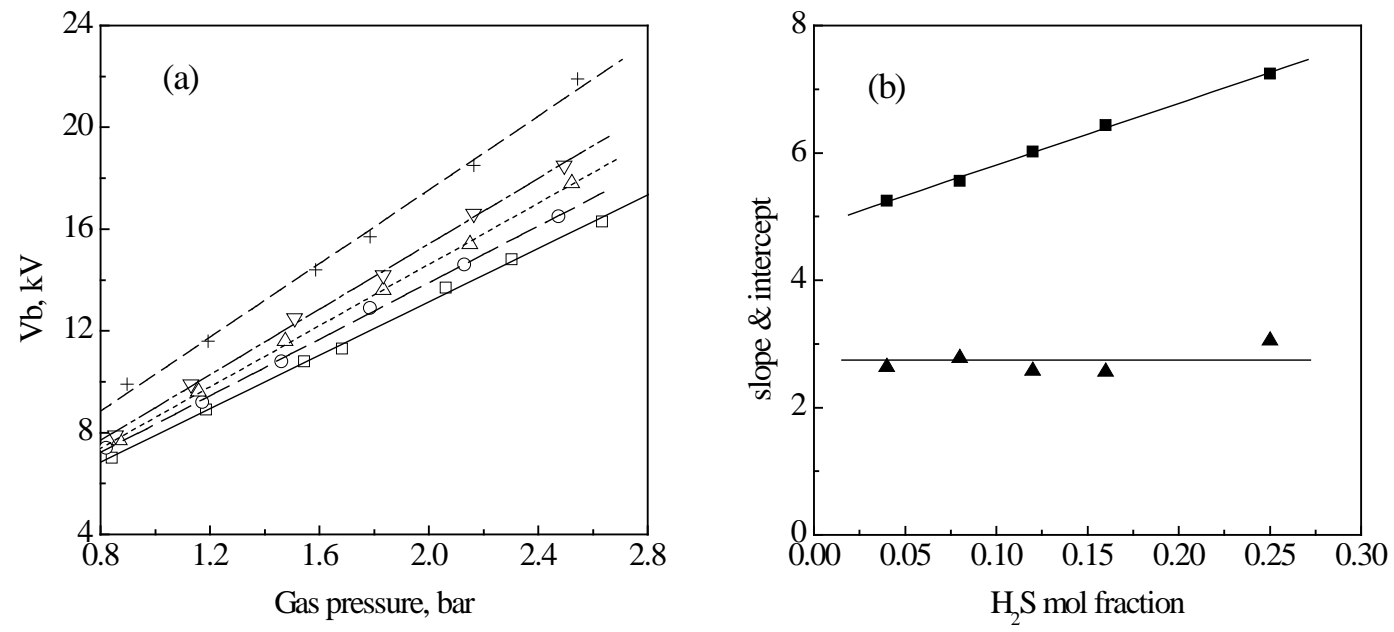

Figure 4. Breakdown voltage of $\mathbf{H}_{2} \mathrm{~S}$ in $\mathbf{H}_{2}$. (a) Breakdown voltage as a function of total gas pressure. Experimental data: $(\square): 4 \% \mathrm{H}_{2} \mathrm{~S},(\bigcirc): 8 \% \mathrm{H}_{2} \mathrm{~S},(\triangle): 12 \% \mathrm{H}_{2} \mathrm{~S},(\nabla): 16 \% \mathrm{H}_{2} \mathrm{~S},(+)$ : $25 \% \mathrm{H}_{2} \mathrm{~S}$; linear regression: (-): $4 \% \mathrm{H}_{2} \mathrm{~S},(--)$ : $8 \% \mathrm{H}_{2} \mathrm{~S},(\cdots): 12 \% \mathrm{H}_{2} \mathrm{~S},(-\cdot-): 16 \% \mathrm{H}_{2} \mathrm{~S}$, (---): $25 \% \mathrm{H}_{2} \mathrm{~S}$. (b) Slope and intercept from linear regression in (a) as a function of $\mathrm{H}_{2} \mathrm{~S}$ mole fraction. (ם): slope $\mathrm{m}_{\mathrm{i}} ;(\boldsymbol{\Delta})$ : intercept $\mathrm{n}_{\mathrm{i}}$. 


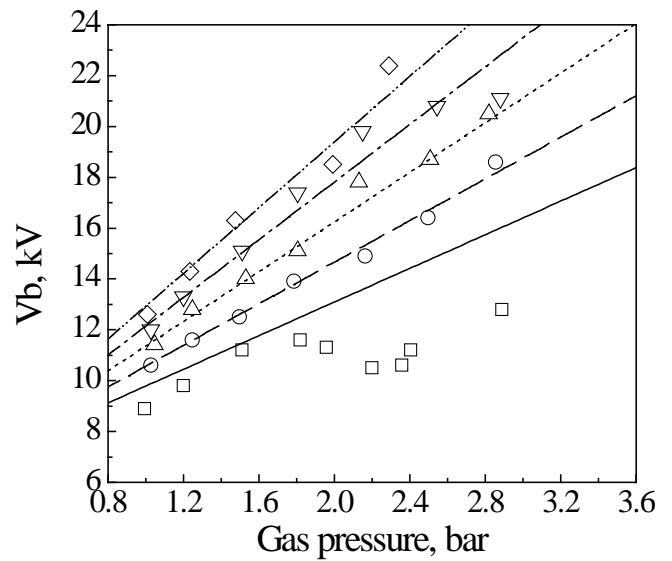

(a) $\mathrm{H}_{2} \mathrm{~S}$ in $\mathrm{Ar}$

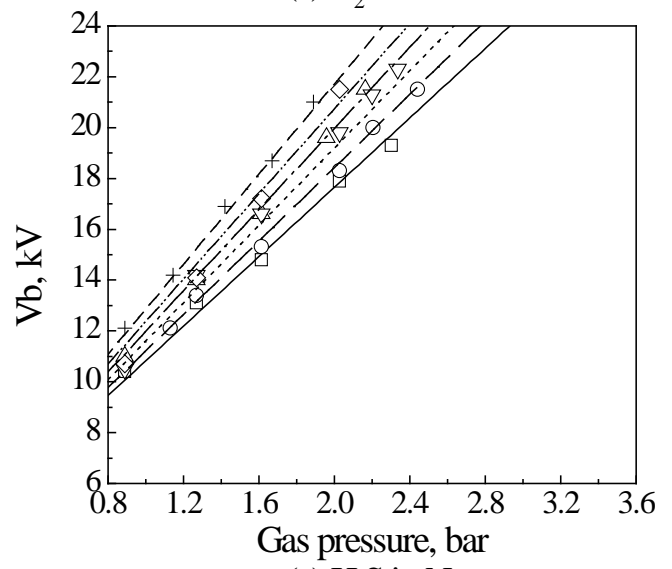

(c) $\mathrm{H}_{2} \mathrm{~S}$ in $\mathrm{N}_{2}$

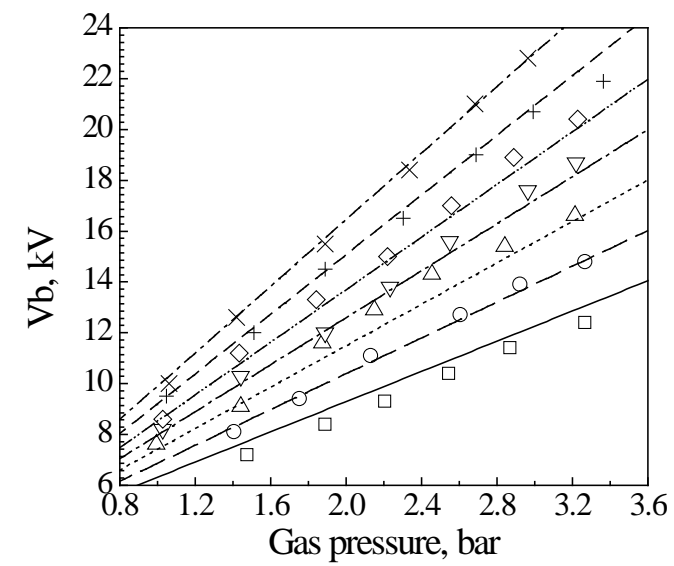

(b) $\mathrm{H}_{2} \mathrm{~S}$ in $\mathrm{He}$

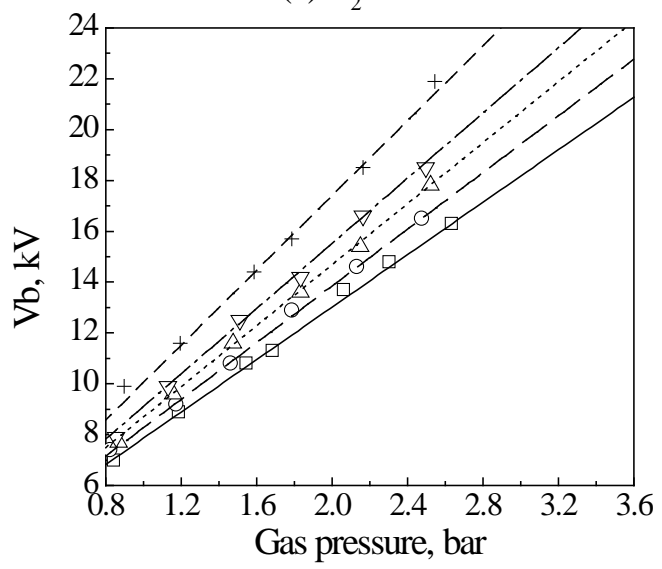

(d) $\mathrm{H}_{2} \mathrm{~S}$ in $\mathrm{H}_{2}$

Figure 5. Breakdown voltage as a function of total gas pressure. (a) $\mathrm{H}_{2} \mathrm{~S}$ in $\mathrm{Ar}$; (b) $\mathrm{H}_{2} \mathrm{~S}$ in He; (c) $\mathrm{H}_{2} \mathrm{~S}$ in $\mathrm{N}_{2}$; (d) $\mathrm{H}_{2} \mathrm{~S}$ in $\mathrm{H}_{2}$

Experimental data: $(\square): 4 \% \mathrm{H}_{2} \mathrm{~S} ;(\bigcirc): 8 \% \mathrm{H}_{2} \mathrm{~S} ;(\triangle): 12 \% \mathrm{H}_{2} \mathrm{~S} ;(\nabla): 16 \% \mathrm{H}_{2} \mathrm{~S}$;

$(\diamond): 20 \% \mathrm{H}_{2} \mathrm{~S} ;(+): 25 \% \mathrm{H}_{2} \mathrm{~S} ;(\times): 30 \% \mathrm{H}_{2} \mathrm{~S}$

Calculated data: (-): $4 \% \mathrm{H}_{2} \mathrm{~S} ;(--): 8 \% \mathrm{H}_{2} \mathrm{~S} ;(\cdots)$ : $12 \% \mathrm{H}_{2} \mathrm{~S} ;(-\cdot-)$ : $16 \% \mathrm{H}_{2} \mathrm{~S}$;

$(-\cdots-): 20 \% \mathrm{H}_{2} \mathrm{~S} ;(---): 25 \% \mathrm{H}_{2} \mathrm{~S} ;(-\cdot-)$ : $30 \% \mathrm{H}_{2} \mathrm{~S}$ 

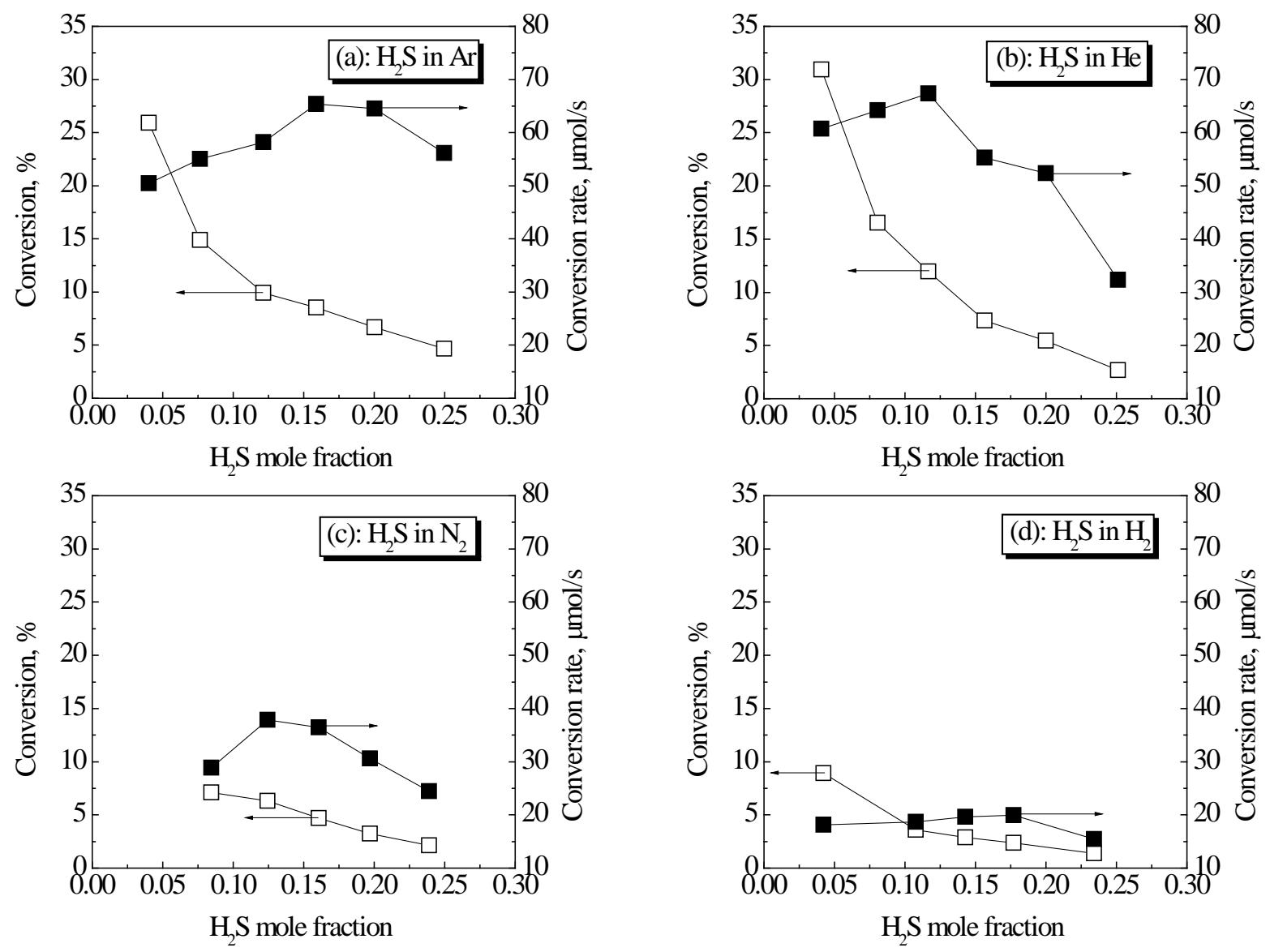

Figure 6. $\mathrm{H}_{2} \mathrm{~S}$ conversion and conversion rate as a function of $\mathrm{H}_{2} \mathrm{~S}$ mole fraction in different balance gases. $(\square)$ : conversion, $(\square)$ : conversion rate 


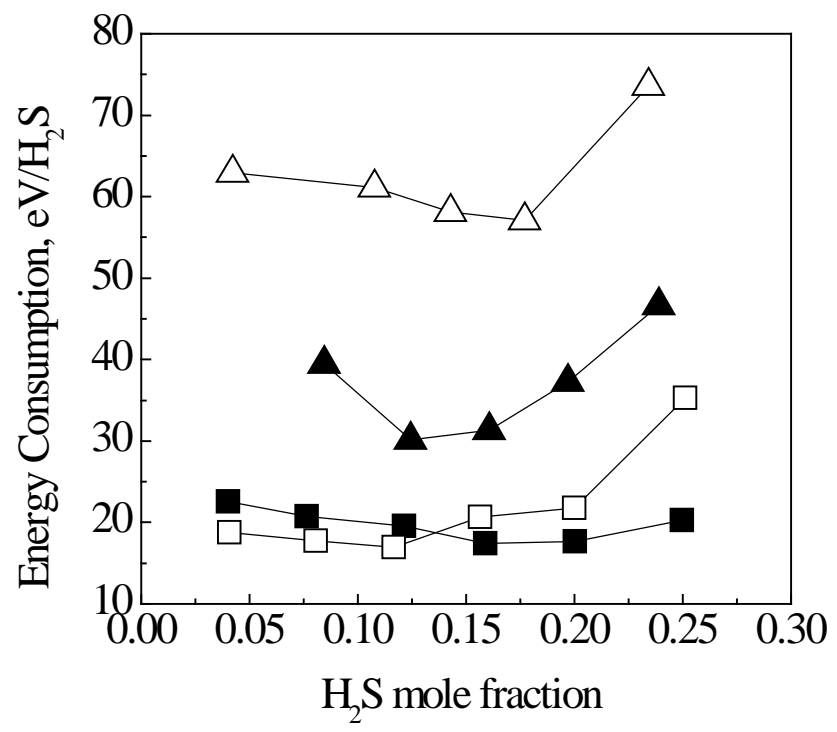

Figure 7. Energy consumption of $\mathrm{H}_{2} \mathrm{~S}$ conversion as a function of $\mathrm{H}_{2} \mathrm{~S}$ mole fraction in

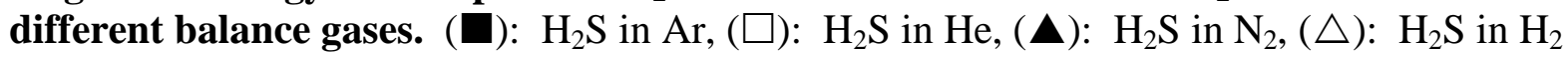

